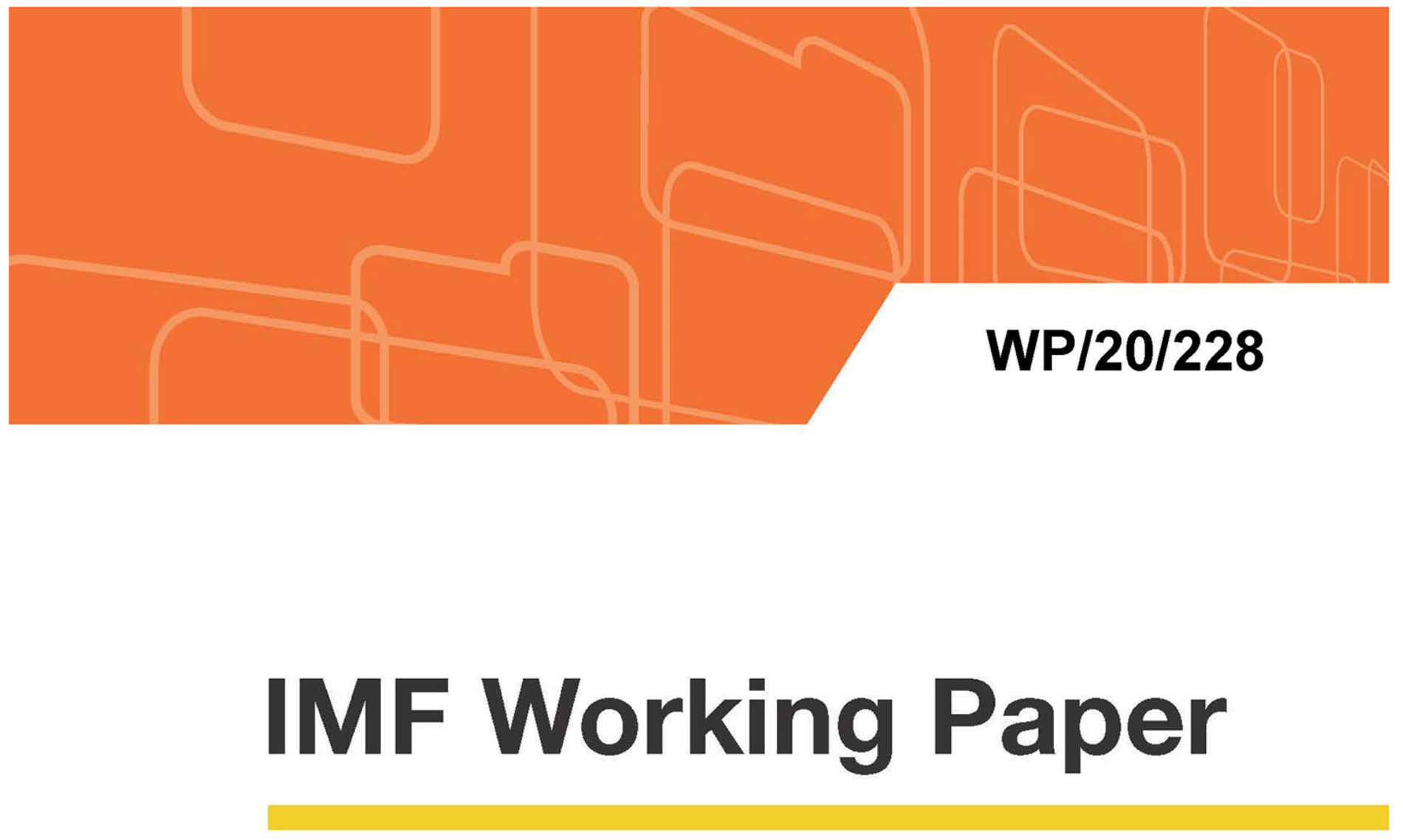

\title{
Crouching Beliefs, Hidden Biases: The Rise and Fall of Growth Narratives
}

by Reda Cherif, Marc Engher, and Fuad Hasanov

IMF Working Papers describe research in progress by the author(s) and are published to elicit comments and to encourage debate. The views expressed in IMF Working Papers are those of the author(s) and do not necessarily represent the views of the IMF, its Executive Board, or IMF management. 


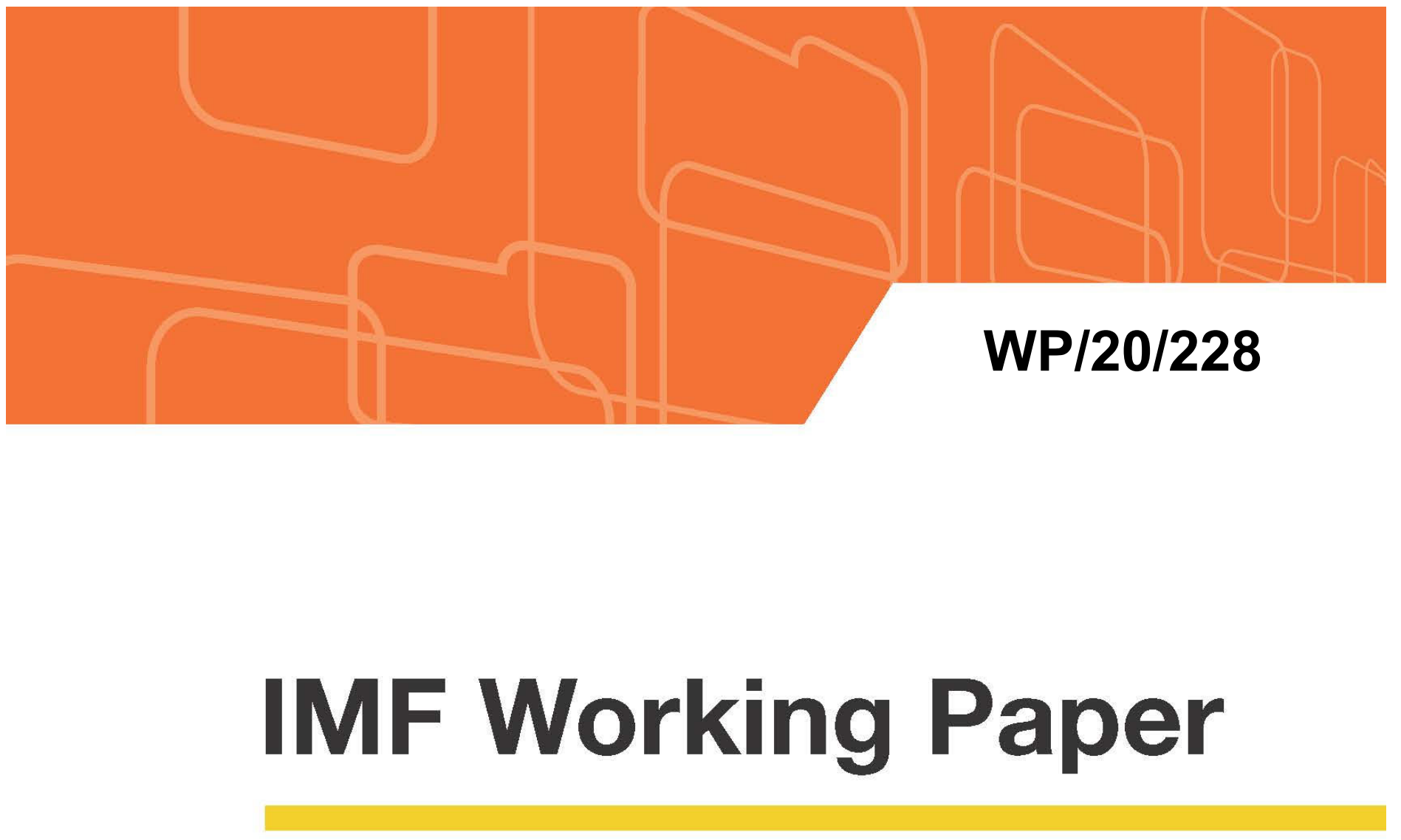

\section{Crouching Beliefs, Hidden Biases: The Rise and Fall of Growth Narratives}

by Reda Cherif, Marc Engher, and Fuad Hasanov

IMF Working Papers describe research in progress by the author(s) and are published to elicit comments and to encourage debate. The views expressed in IMF Working Papers are those of the author(s) and do not necessarily represent the views of the IMF, its Executive Board, or IMF management.

$$
\text { I N T E R N A T | O N A L M O N E T A R Y F U N D }
$$


IMF Working Paper

Institute for Capacity Development

\title{
Crouching Beliefs, Hidden Biases: The Rise and Fall of Growth Narratives \\ Prepared by Reda Cherif, Marc Engher, and Fuad Hasanov ${ }^{1}$
}

Authorized for distribution by Rahul Anand

November 2020

\section{IMF Working Papers describe research in progress by the author(s) and are published to elicit comments and to encourage debate. The views expressed in IMF Working Papers are those of the author(s) and do not necessarily represent the views of the IMF, its Executive Board, or IMF management.}

\begin{abstract}
The debate among economists about an optimal growth recipe has been the subject of competing "narratives." We identify four major growth narratives using the text analytics of IMF country reports over 1978-2019. The narrative "Economic Structure"-services, manufacturing, and agriculture - has been on a secular decline overshadowed by the "Structural Reforms" - competitiveness, transparency, and governance. We observe the rise and fall of the "Washington Consensus" - privatization and liberalization - and the rise to dominance of the "Washington Constellation," a collection of many disparate terms such as productivity, tourism, and inequality. Growth theory concepts such as innovation, technology, and export policy have been marginal while industrial policy, which was once perceived positively, is making a comeback.
\end{abstract}

JEL Classification Numbers: O25, O0, N1

Keywords: Narratives; industrial policy; growth; manufacturing; services; Washington Consensus; structural reforms

Authors’ E-Mail Addresses: acherif@,imf.org; mengher@,imf.org; fhasanov@,imf.org

\footnotetext{
${ }^{1}$ We are grateful to Jojo Zhao for an excellent research assistance. We would also like to thank Rahul Anand, Romain Duval, Yun Liu, Ippei Shibata, and Andrew Warner for helpful comments. We are grateful to Talia Zulueta for formatting the paper. All errors are our own.
} 
ABSTRACT

I. INTRODUCTION

\section{DATA AND METHODOLOGY: SIFTING THROUGH FORTY YEARS OF IMF COUNTRY REPORTS}

III. GROWTH NARRATIVES: CROUCHING BELIEFS, HIDDEN BIASES

A. Services or Manufacturing Fetishism?

B. One Growth Recipe for All?

C. Identifying Growth Narratives and Their Cycles

D. Clusters as Narratives

E. The Rise and Fall of Growth Narratives

F. Industrial Policy: The Forgotten Narrative

IV. CONCLUSION

REFERENCES

\section{FIGURES}

Figure 1. Coverage of IMF Country Reports (1978-2019)

Figure 2. Pooled Growth Recipe Word Cloud

Figure 3. All Economies Word Cloud

Figure 4. Advanced Markets Word Cloud

Figure 5. Emerging Markets Word Cloud

11

Figure 6. Low-Income Countries Word Cloud

Figure 7. Relative Heatmap and Clusters' Peaks

Figure 8. Absolute Heatmap and Clusters' Concentration

Figure 9. The 'Economic Structure' Narrative

Figure 10. The 'Washington Consensus' Narrative

Figure 11. The Structural Reforms Narrative

Figure 12. The 'Washington Constellation' Narrative

Figure 13. Total Frequencies of Growth Narratives for All Economies

Figure 14. Endogenous Structural Breaks in the Trends

Figure 15. Endogenous Structural Breaks in the Trends

Figure 16. Endogenous Structural Breaks in the Trends

Figure 17. Endogenous Structural Breaks in the Trends

Figure 18. 'Industrial Policy' Over Time

$\longrightarrow \frac{21}{21}$
$\longrightarrow \frac{22}{23}$
$\frac{24}{24}$

\section{TABLES}

Table 1: Correlation Matrix of Clusters 


\section{INTRODUCTION}

Our world is shaped by ideas, and the ideas of economists are particularly influential. Keynes observed that "the ideas of economists and political philosophers, both when they are right and when they are wrong, are more powerful than is commonly understood. Indeed, the world is ruled by little else." But why are some ideas more influential than others? And why does their influence rise and fall? Empirical evidence and coherent theories must play a role but ultimately, they cannot be the only explanation when it comes to debates that are far from settled such as the causes of economic growth.

Narratives and the ideas that shape the narratives affect our worldview and influence our decisions. Shiller (2019) in his Narrative Economics emphasizes the importance of narratives or popular stories and their impact on economic outcomes such as the severity of a downturn or technological unemployment. In the same fashion, the formation of a consensus among economists is closely related to the success of a certain narrative. This in turn is not inconsistent with the possibility that widespread narratives among professional economists can be informed by facts or based on economic theories. In this paper, we attempt to identify the main narratives related to economic growth and how their relative influence evolved through time. In other words, we consider narratives among economists from an epistemological point of view.

Understanding the wealth of nations and the determinants of economic growth is one of the central questions in economics. Guided by theory and backed by data, policymakers attempt to devise appropriate growth policies. However, there are several competing theories and different ways to interpret empirical evidence as to what truly causes growth. For instance, many economists may have in mind the seminal paper by Lucas (1988) that emphasizes the role of human capital. ${ }^{2}$ Other theories emphasize capital accumulation (e.g. Solow 1956), financial development (e.g. Greenwood and Jovanovic 1990), institutions (e.g. Acemoglu and Robinson 2012), ideas and innovation to produce new goods (e.g. Romer 1990), and Schumpeterian creative destruction or quality ladders (e.g. Aghion and Howitt 1992). But influential economists in the past such as Leontief (1966), who introduced the concept of input-output tables, or Galbraith (1967), who emphasized the role of large firms and industries requiring advanced technology and planning, had a largely different focus.

All these ingredients and others are likely to be important in the growth recipe, but policymakers operate under resource, time, and capacity constraints. The list of probable causes of growth is going to be long. Instead of producing an exhaustive list, policymakers ought to establish priorities with the precise policies and resources needed to achieve their goals. In other words, they need to come up with a limited set of easily expressed explanations or stories as to what causes growth. These constitute economic narratives as defined by Shiller (2017), which we describe as "growth narratives" in our context.

\footnotetext{
${ }^{2}$ Even if one accepts the result that more skills and education would increase growth, policymakers are still left in the dark as to what exactly should be done to increase "human capital."
} 
Uncovering the composition of the prevalent growth recipe, or a set of growth narratives and their respective importance, would help identify the main economic theory and empirical evidence behind it. It would help bridge the gap between economics as a discipline and how policymakers understand it. It could allow us to explore the views of professional economists about growth over time and identify key growth narratives as Shiller (2019) has emphasized.

We propose to uncover the composition of the prevalent growth recipe in the world using the text analytics of IMF country reports over 1978-2019 (available online since 2000). The IMF produces a multitude of reports, in particular country reports-Article IV Staff Reportswhich cover practically the whole world on a regular basis (a country report is issued every one to two years on average for every member country) and reflect recent developments in the economy, a discussion of the policies pursued, and the views of the authorities and IMF staff on macroeconomic policies. Our analysis is based on a set of 4620 country reports over 1978-2019, covering most of the IMF membership. These reports are a good reflection of the consensus, or the "orthodoxy" as some would call it, on economic issues among professional economists in academia and policy circles. Moreover, unlike journal articles, these reports are intended for a relatively wide audience beyond academia, including policymakers, financial sector analysts, and journalists. As such, they are likely to distill sophisticated ideas in the form of narratives or stories for effective communication. ${ }^{3}$ This study of narratives thus reflects the mainstream economists' views on growth as captured by these clusters. ${ }^{4}$

Using a vocabulary of 113 distinct terms relevant to growth theory and policy, we compute relative term frequencies in the reports. We use terms we believe are the main growth recipe ingredients. These terms span a wide spectrum of growth terminology such as "Infrastructure," "Governance," and "Education". The list is also narrow enough to avoid terms that are too general such as "monetary policy" or "fiscal policy" or not directly related to growth. Moreover, many of these terms are relevant to issues other than economic growth, but ultimately, they are tied to growth whether explicitly or implicitly. For example, infrastructure could be mentioned in the context of fiscal policy but the effect of infrastructure on growth would be part of the tradeoff with fiscal sustainability. We then compute the total occurrences of each term in three pooled subgroups of reports: LowIncome Countries (LICs), Emerging Markets (EMs), and Advanced Markets (AMs). Finally, we obtain the frequency of each term relative to all the terms in the set, which would inform us on the "dosage" of each ingredient in the full recipe.

A study of relative frequencies offers a sketch of the growth recipe and we find that on average the recipe is similar across all income groups, but it changes over time. Some main ingredients are privatization, governance, transparency, infrastructure, and education. Notably, the frequency of governance and transparency rose sharply in the late 1990s and remained at a high level. In comparison, innovation, technology, industrialization, and export policy have been, by and large, ignored. In terms of sectors, services have dominated

\footnotetext{
${ }^{3}$ Economists in International Financial Institutions are mostly holders of $\mathrm{PhDs}$ from major Western universities and are likely to share the consensus in the economics profession.

${ }^{4}$ Since these clusters are composed of distinct words and phrases, without context, they may not be interpreted as IMF policy advice; rather they reflect the key ideas and concepts discussed.
} 
manufacturing and agriculture by a large margin. In particular, tourism is a major ingredient for all income categories, including AMs. In parallel, the frequency of industrialization and industry has been declining since the mid-1980s. Finally, industrial policy, although it appeared at a relatively low frequency, was mostly perceived positively until the late 1980s in the context of AMs. It subsequently faded away until the recent years when it seems to be making a comeback.

Using hierarchical clustering, we have identified and examined four key growth narratives that make up the prevalent growth recipe and how the latter has changed through time. We find a cluster consisting almost exclusively of terms related to industrial sectors such as services, manufacturing, construction, and agriculture. We interpret it as corresponding to an "Economic Structure" narrative focusing on the study of each industrial sector and their interlinkages (e.g., Leontief 1966). This narrative was the dominant one until the mid-1990s. Another cluster includes terms broadly related to structural reforms such as institutions, governance, transparency, and competition. We describe this cluster as the "Structural Reforms" narrative, in which growth is largely explained by the quality of institutions and regulatory framework (e.g., Acemoglu and Robinson 2012). This narrative was the most influential in the 2000s although was still relatively important in the late 2010s.

The other two clusters are "Washington Consensus" and "Washington Constellation." A cluster mostly consisting in privatization/privatize and liberalization/liberalize terms is interpreted as corresponding to the "Washington Consensus" narrative. This narrative is based on the principle that privatization and liberalization are beneficial because private industry is managed more efficiently than state enterprise (Williamson 1990). This narrative was marginal until the mid-1980s, when it subsequently rose, peaked in the 1990s at the time of the transition of many socialist economies, then fell in the early 2000 s to marginal again. The final cluster is a collection of many disparate terms such as productivity, tourism, business environment, doing business, infrastructure, skills, and access to finance. We describe the narrative associated with this cluster as the "Washington Constellation." Seemingly unrelated concepts can be bundled into a single narrative (Shiller 2019). As observed by Shiller, the celestial constellations we see have no objective reason to be clustered together, but they form patterns and provide a meaning for the beholder. In this narrative, growth can be affected by many factors. The relative weight of this narrative has been rising since the late 1990 s to become the largest one by late 2010 s.

Finally, we identify a set of significant turning points in the relative influence of these narratives and find that they correspond to major political and economic events. The year 1984 marks the beginning of the rise of the "Washington Consensus" and "Structural Reforms" narratives and the decline of the "Economic Structure" confirming the plausible influence of the second Reagan administration in diffusing free market ideas. The year of the Asian crisis, 1997, marks the beginning of the rise of the "Washington Constellation," followed shortly thereafter by the rapid decline of the "Washington Consensus."

We interpret these clusters as representative of "narratives" underpinned by ideas and concepts that shape them. These clusters capture a set of disparate concepts that rise and fall together, and their composition can convey the dominant story or narrative. Like in the principal component or factor analysis, we assign names to these clusters based on their 
composition. The forces behind the formation of the clusters could be attributed to evolving economic theories and new empirical evidence. It could be also the result of political and social changes, which in turn drive economic discussion and policy.

In same vein, changes in the pattern of the relative importance of the clusters may reflect the acceptance or rejection of economic theories, facts or popular stories as emphasized by Shiller (2019). For instance, the "privatization" frequency has started rising rapidly since 1984 and peaked in 1997 while worldwide privatization revenues were relatively stable in the mid-80s to early-90s and started picking up after the mid-90s (Estrin and Pelletier 2018). In addition, at times of uncertainty, financial markets may react substantially to uninformative news as it was the case in the wake of the COVID-19 pandemic (Mamaysky 2020).

The remaining of the paper is as follows. Section II describes the data and methodology. Section III summarizes the findings, and section IV concludes.

\section{Data ANd Methodology: Sifting Through Forty Years OF IMF COUnTRY REPORTS}

To study growth narratives as reflected by the average professional economist, we use the collection of the IMF Article IV Staff Reports over 1978-2019. The sample consists of 4620 reports with 110 reports per year on average (Figure 1). The collection on average contains 26 reports in the advanced market group (AM), 50 reports in the emerging market group (EM), and 34 reports in the low-income country group (LIC). The coverage is representative across income groups.

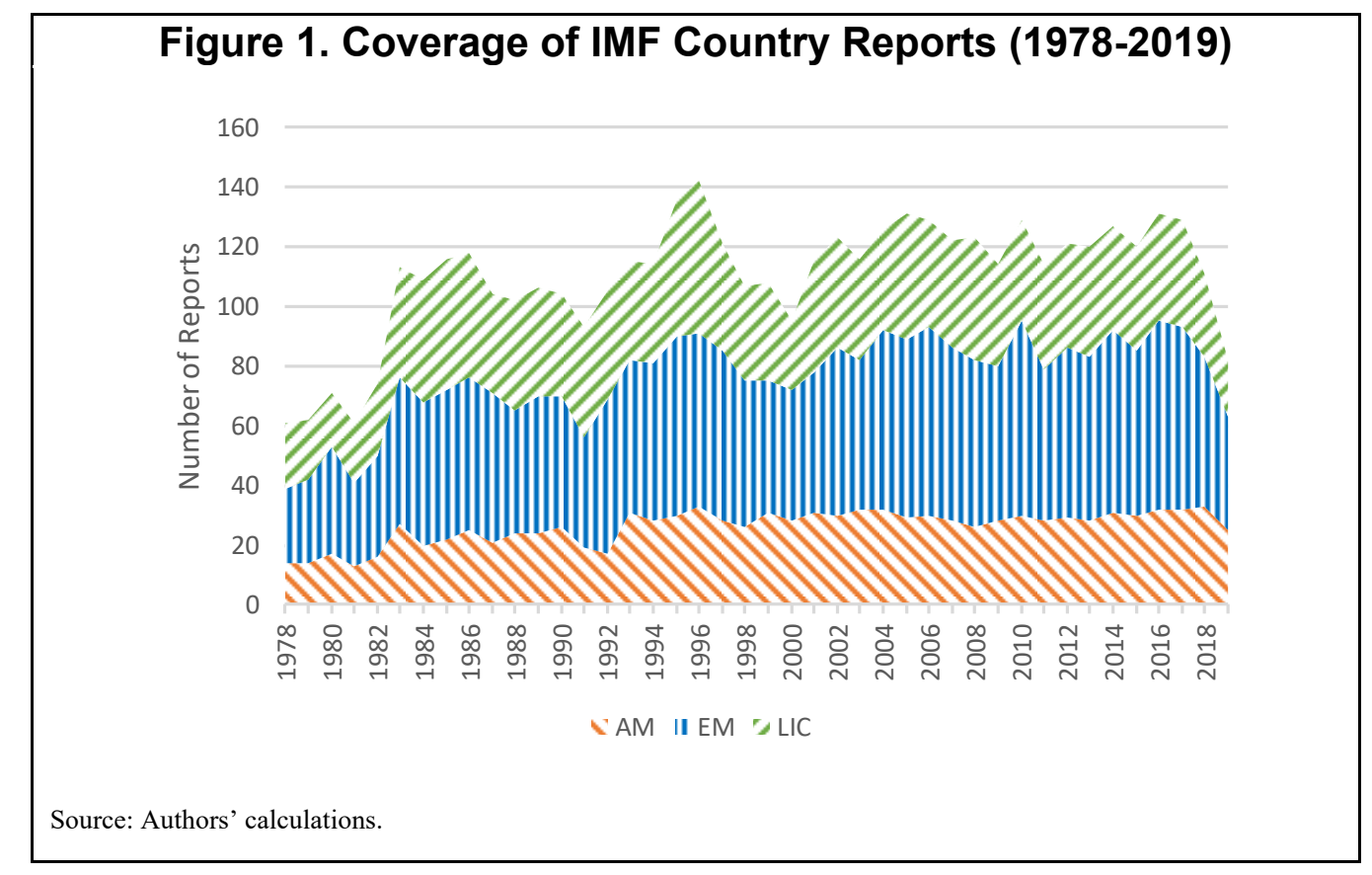


Before running the text analytics, we first create the text data. The reports are transformed from pdf to xml format. ${ }^{5}$ Each document is identified by its country code and the IMF's World Economic Outlook (WEO) group (AM, EM, or LIC) and is defined as a sequence of paragraphs (a string of characters). The standard cleaning of the text is done by deleting punctuation, tables, figures, stop words, etc.

To analyze the context of the documents, we use the input vocabulary of 123 terms pertaining to growth theory and policy. Abbreviated terms and synonyms are combined to give a total of 113 final terms (e.g., Foreign Direct Investment and FDI). The terms used are shown in Appendix Table 1. For instance, we use words related to the sectoral composition such as manufacturing and services, growth theory such as human capital, infrastructure, institutions, and productivity, and growth policy such as structural reforms, liberalization, and industrial policy.

Once the text data are prepared, we use the input vocabulary to compute the term frequencies in the collection of reports. The frequency of each term in the collection is defined as the ratio between the count of term $i$ in all documents and the count of all terms in all documents. The frequencies are computed on an annual basis. More precisely, let $V$ be the input vocabulary and $D$ be the collection of reports. Let $t_{p, d}^{i}$ be the count of occurrences of term $i$ in document $d$ for period $p$. The frequency of term $i$ for period $p, f_{p}^{i}$, is defined by:

$$
f_{p}^{i}=\frac{\sum_{d \in D} t_{p, d}^{i}}{\sum_{k \in V} \sum_{d \in D} t_{p, d}^{k}} \text { with } \sum_{i} f_{p}^{i}=1
$$

We also compute the frequency of each term in the collection of income groups defined as the ratio between the count of term $i$ in all documents of a given income group and the count of all terms in all documents in the same group. The frequency of term $i$ for period $p$ in income group $g$ (a collection of countries, $C$ ), $f_{p, g}^{i}$, is defined by:

$$
f_{p, g}^{i}=\frac{\sum_{\substack{d \in g \\ g \subseteq C}} t_{p, d}^{i}}{\sum_{k \in V} \sum_{\substack{d \in g \\ g \subseteq C}} t_{p, d}^{k}}
$$

\section{Growth Narratives: Crouching Beliefs, Hidden Biases}

\section{A. Services or Manufacturing Fetishism?}

Some observers believe that politicians and economists are obsessed with manufacturing. ${ }^{6}$ In contrast, examining the pooled cross-section of all reports over the 1978-2019 period, we find that the term "services" accounts for the largest share of all the terms in our input vocabulary. In fact, across all countries and years, the occurrence of this term comprises about 20 percent of the occurrence of all input terms (Figure 2). Across the income groups,

\footnotetext{
${ }^{5}$ The conversion process is made by a software product PdfLib. The quality and precision of the conversion are sufficient for the purpose of this study.

${ }^{6}$ See, for example, John Kay's commentary (2012).
} 
the least occurrence is 14 percent in advanced economies and the most occurrence, 24 percent, is in low-income group. In emerging markets, it is similar to the total occurrence of about 19 percent. Even after controlling for "financial services," the occurrence of "services" is large. "Financial services" appears in a meagre 0.4 percent of occurrences across all countries and years. More important, we have included other service sectors in our vocabulary as separate terms such as tourism, which on its own has a sizable frequency.

Examining the terms describing sectors, "agriculture" and "agricultural", much smaller than services, comprise the second largest component of these occurrences, followed closely by "industry" and "industrial." Overall, agriculture is about 7 percent of the vocabulary although it varies across the income groups. Surprisingly, agriculture appears at a sizable frequency in advanced markets, about 3.5 percent. The EM group has a frequency of 6.5 percent while for the LIC group, it is about 10.5 percent. Industry terms appear 10 percent of the time in AMs while about 6 percent in EMs and LICs. Similarly, "manufacturing" appears twice as often in AMs, about 5 percent, as in EMs and LICs.

One of the sectors that tends to get a lot of attention - tourism - is discussed quite frequently, on average about 2.5 percent. Interestingly, the term appears relatively often in both AMs and LICs, about 1.5 percent of all term occurrences, which places it in the top 20 most frequently occurring words, excluding services. In EMs, the frequency jumps to 4 percent, which is in the top 5 frequencies.

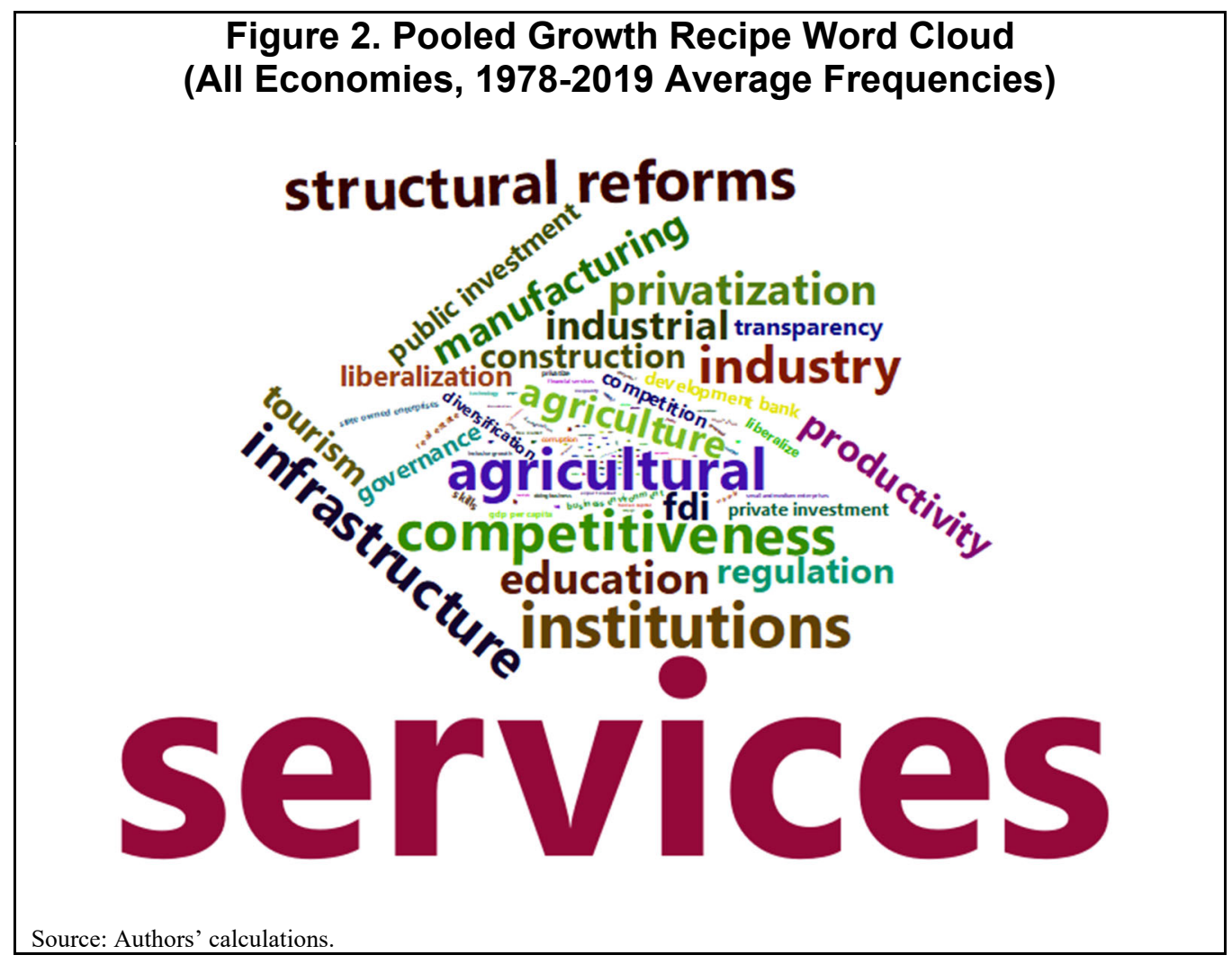


Overall, the discussion of services is much more prevalent than that of manufacturing or other industries. Although some discussion about these terms in the reports could relate to balance of payments and other economic topics, comparing the frequencies of these terms to each other largely encompasses their relative importance in the discussion about growth. And as shown, services have been a focus of the discussion throughout more than four decades and across income groups. This includes periods when manufacturing or agriculture used to be large sectors in terms of production and employment. . These results suggest that despite manufacturing being an important driver of growth (e.g. Hausmann, Hwang, and Rodrik 2007, Rodrik 2013, and Cherif and Hasanov 2019), most of the discussion has been focused around services in most countries most of the time. The focus on tourism than manufacturing in EMs is noteworthy. In contrast, in AMs, the appearance of manufacturing is much more prevalent although development theory would suggest that it should be more important for discussions in EMs and LICs.

\section{B. One Growth Recipe for All?}

The top 10 terms by average frequency indicate substantial similarities across income groups. Such terms as structural reforms, institutions, industry, and privatization appear in all income groups (Figures 3-6). Competitiveness appears in the top 10 terms in AMs and EMs, while education, infrastructure, and agricultural appear in EMs and LICs. ${ }^{7}$

Concepts associated with exogenous growth theory (e.g., Solow 1956) feature far more often than those from endogenous growth theory (e.g., Romer 1990). Key drivers of growth from endogenous growth theory such as "innovation" and "technology" and from development theory such as "industrialization" and "export-orientation" or "export promotion" occur with relatively marginal frequencies across all income groups. Productivity is discussed less often in EMs and LICs than AMs, and terms associated with the role of the state in physical and human capital accumulation, such as public investment, infrastructure and education, occur substantially more often than private investment across all income groups.

Economic theory emphasizes both government and market failures in development and growth literature (e.g., Cherif and Hasanov 2019), but the growth recipe discourse seems to focus substantially on government failures. Structural reforms, institutions, and privatization are among the top terms. Transparency, governance, liberalization, and regulation are other frequently used terms. Economic terms that could describe solutions for market failures such as industrial policy, industrialization, or export orientation, are barely featured and have been non-existent for many years.

\footnotetext{
${ }^{7}$ Only a few distinct terms for each group remain such as tourism and FDI in EMs, governance, agriculture, and public investment in LICs, and productivity, manufacturing, industrial, competition, and regulation in AMs.
} 
Figure 3. All Economies Word Cloud

(Excluding Services, 1978-2019)

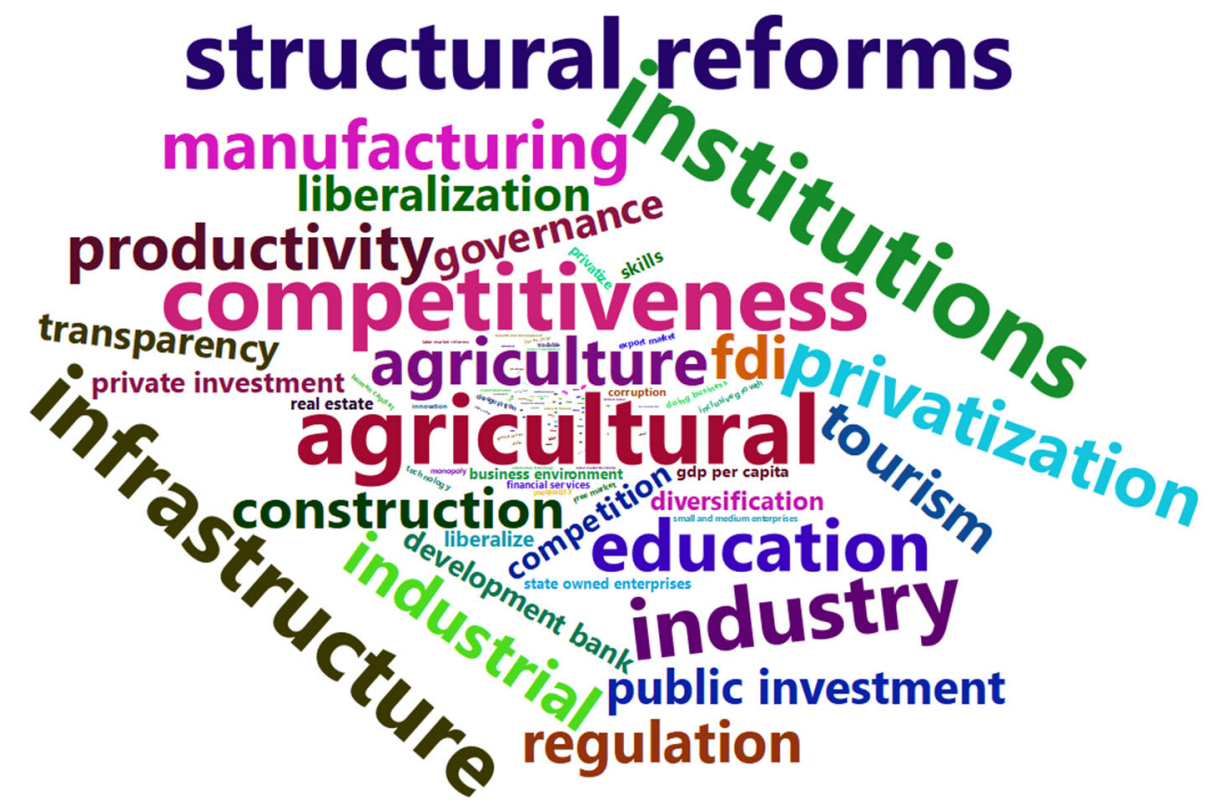

Source: Authors' calculations.

Figure 4. Advanced Markets Word Cloud

(Excluding Services, 1978-2019)

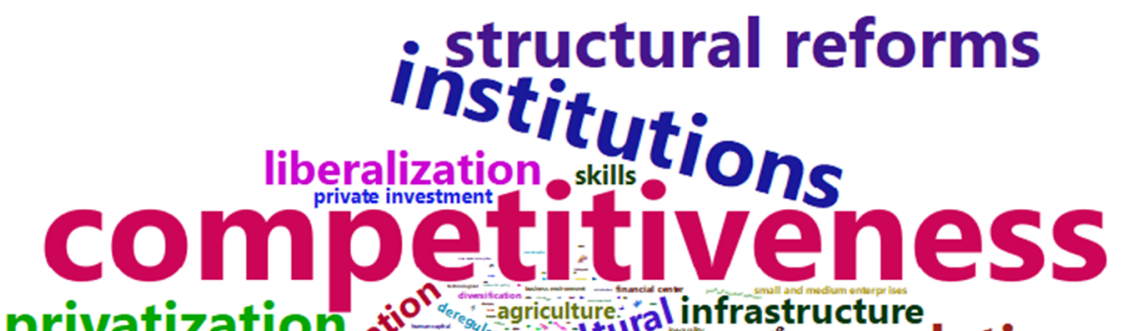

privatization $\mathrm{o}^{\mathrm{i}} \mathrm{o}_{\mathrm{c}}$

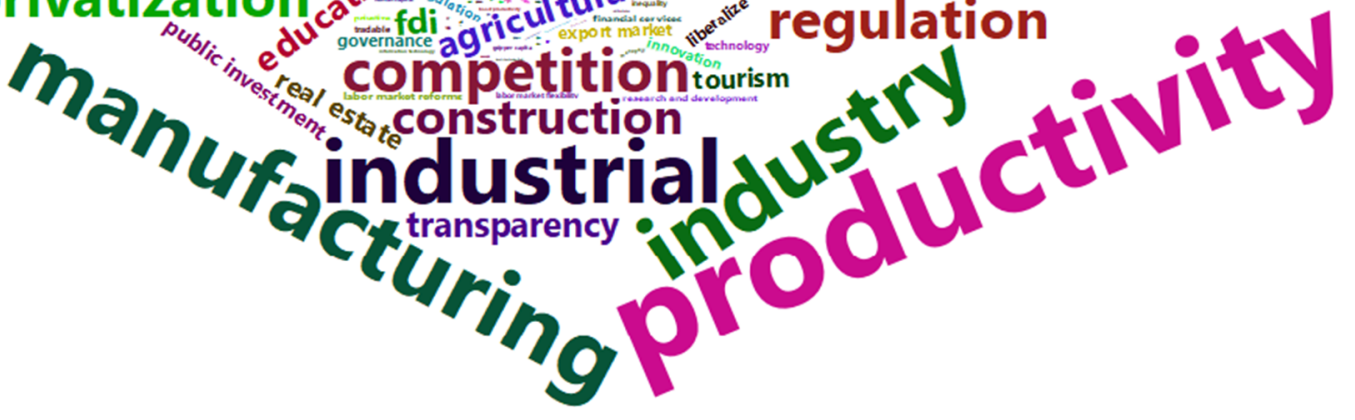

Source: Authors' calculations. 


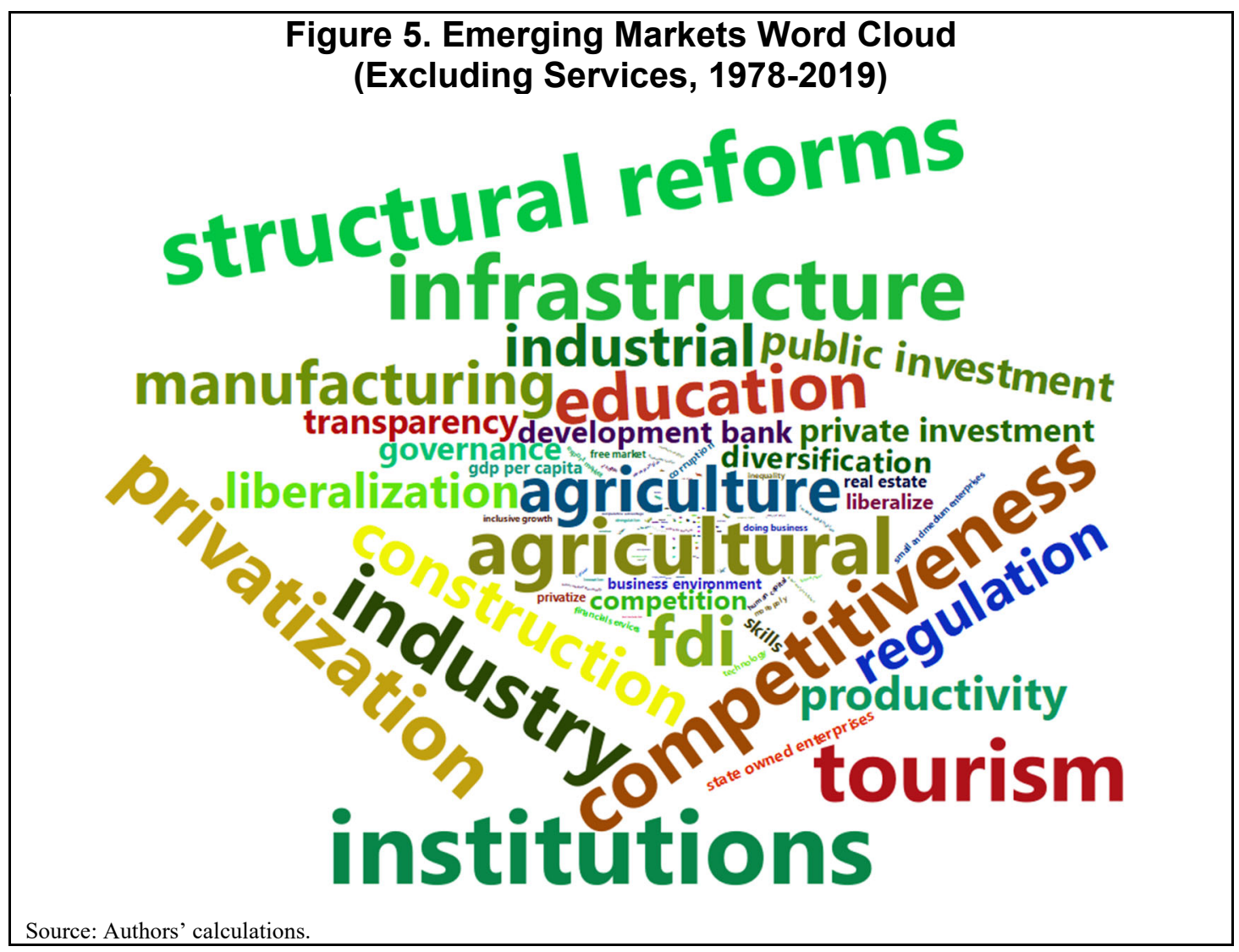

Source: Authors' calculations.

Figure 6. Low-Income Countries Word Cloud (Excluding Services, 1978-2019)

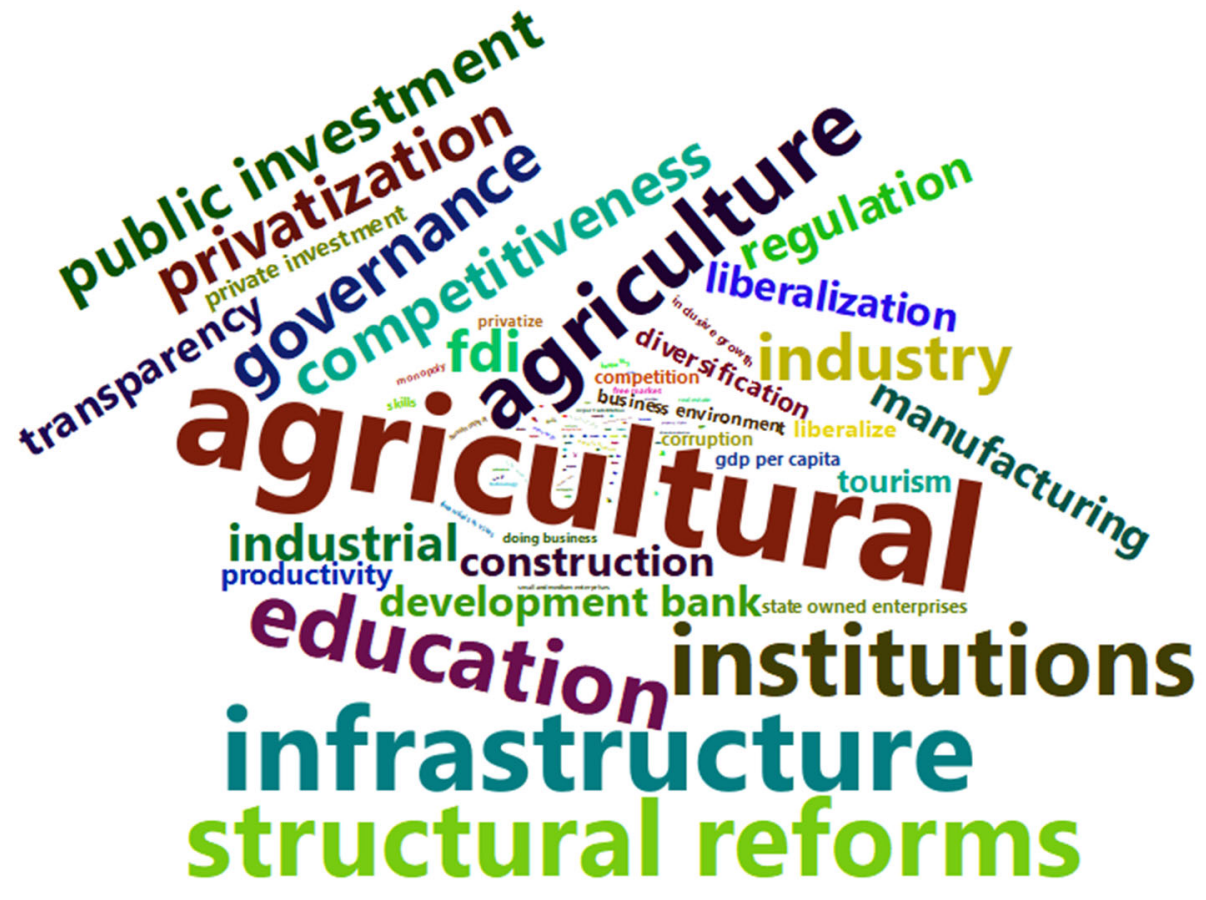

Source: Authors' calculations. 


\section{Identifying Growth Narratives and Their Cycles}

To formally identify growth narratives — and eventually their cycles — we use hierarchical clustering algorithm to cluster the data. Hierarchical clustering allows us to identify clusters without prespecifying the number of clusters in advance. ${ }^{8}$ The terms in our vocabulary, for which we observe frequencies over the years, are classified into clusters based on a dissimilarity measure, and a linkage method is used to define clusters at each step of agglomerating observations. In particular, we use a standard dissimilarity measure, Euclidean distance, and apply Ward's minimum variance method to measure dissimilarities between clusters (Ward 1963)..$^{9}$ Ward's method starts with each observation as a cluster and at each iteration, it finds a pair of clusters to merge that minimizes the total within-cluster variance. We then compute the optimal number of clusters using the "Elbow" method that plots total within-cluster variance against the number of clusters with the bend in the plot indicating the appropriate number of clusters. ${ }^{10}$

To implement clustering analysis, we prepare the data and apply the algorithm. First, we delete a few terms that have extremely low frequencies, that is less than 0.001 percent or are in the lower 5 percent of the tail of the distribution, whichever is greater. For all economies, the terms are credit market regulation, cronyism, good institutions, invention, laissez faire, and robotization. Then, we standardize frequencies to a mean of zero and variance of one. Using standardized frequencies, we compute the dissimilarity matrix and apply Ward's method to classify the terms into different clusters. According to the Elbow method, we obtain 4 clusters. ${ }^{11}$

To illustrate our results, we plot heatmaps of the term frequencies in each cluster or narrative. The first heatmap plots the standardized frequencies and shows the evolution, or cycles, of terms through time (Figure 7). The yellow cells indicate larger numbers or stronger relative occurrences or frequencies of the term. The four clusters shown have distinct patterns over time while displaying relatively similar pattern within each cluster. In other words, terms in each cluster tend to peak at around the same time and the peak is different for each group. The second heatmap plots the actual levels of frequencies, or how large the absolute occurrence or frequency is (Figure 8). The darker blue cells display higher intensity of certain terms within each cluster. The heatmap indicates that a few terms comprise the bulk of the total frequency of each cluster - that is, they are occurring frequently - while most of the other terms are not mentioned much. This concentration within each cluster will be handy in the following section, in which we attempt to interpret the clusters as narratives.

\footnotetext{
${ }^{8}$ In addition, it creates a tree-based representation of the terms, a dendrogram, which indicates diagrammatically the arrangement and relative distance among clusters.

${ }^{9}$ We chose this method among others as it tends to produce relatively balanced clusters.

${ }^{10}$ The method helps identify the optimal number of clusters at which the marginal decrease in variance explained with each extra cluster becomes small, hence forming an elbow in the graph.

11 The optimal number of clusters obtained using the Elbow method is between the numbers produced by two other approaches and seems easier to interpret. Using the silhouette approach, we get 2 optimal clusters, which is too few, while with the gap statistic method, we obtain 9 optimal clusters, which is too many.
} 
Figure 7. Relative Heatmap and Clusters' Peaks (Terms by Standardized Frequency)

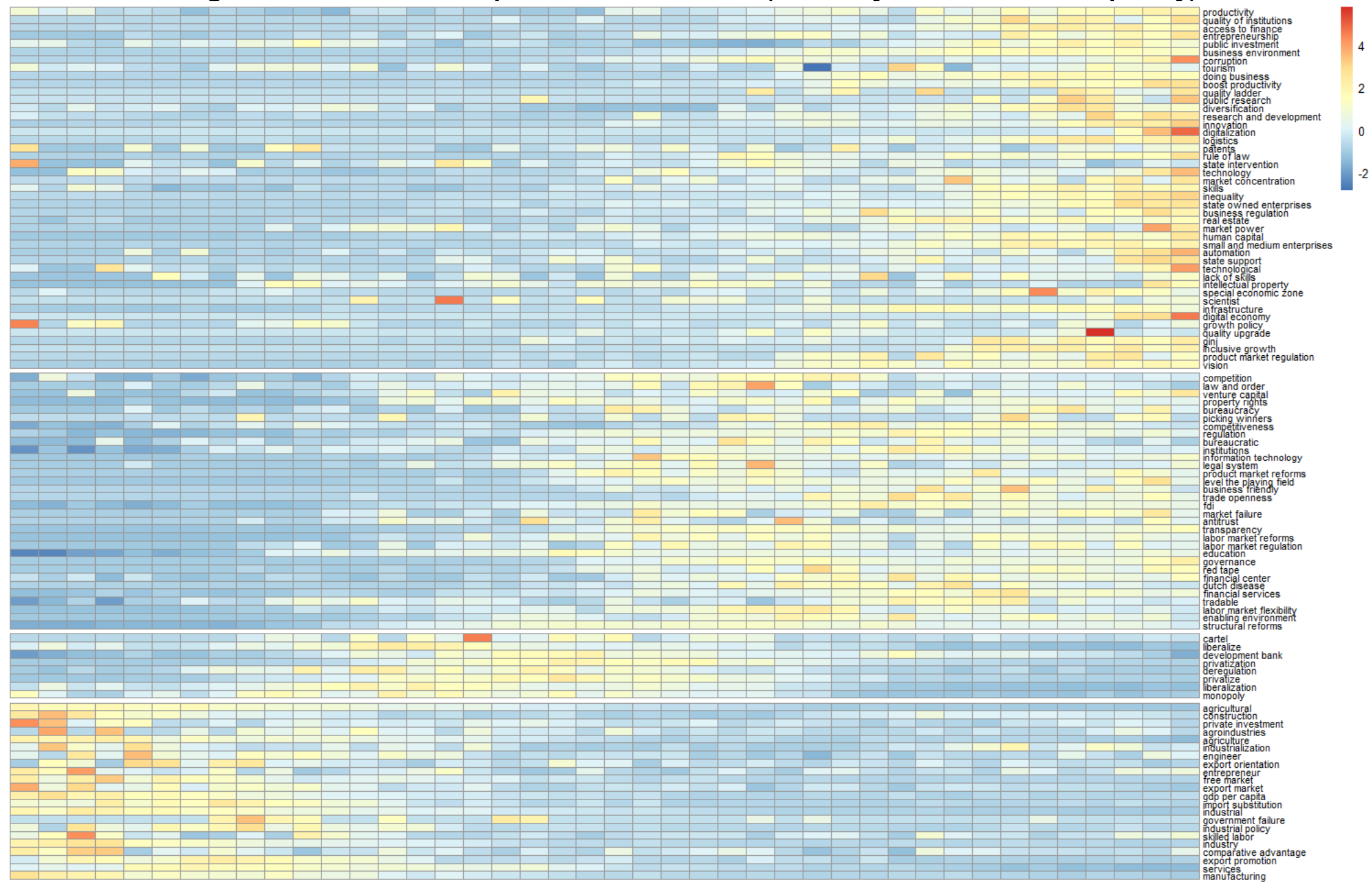

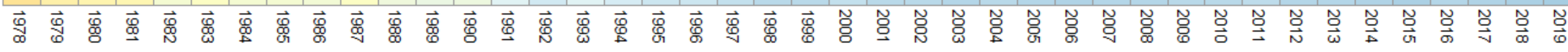


Figure 8. Absolute Heatmap and Clusters' Concentration (Terms by Frequency, Excluding Services)

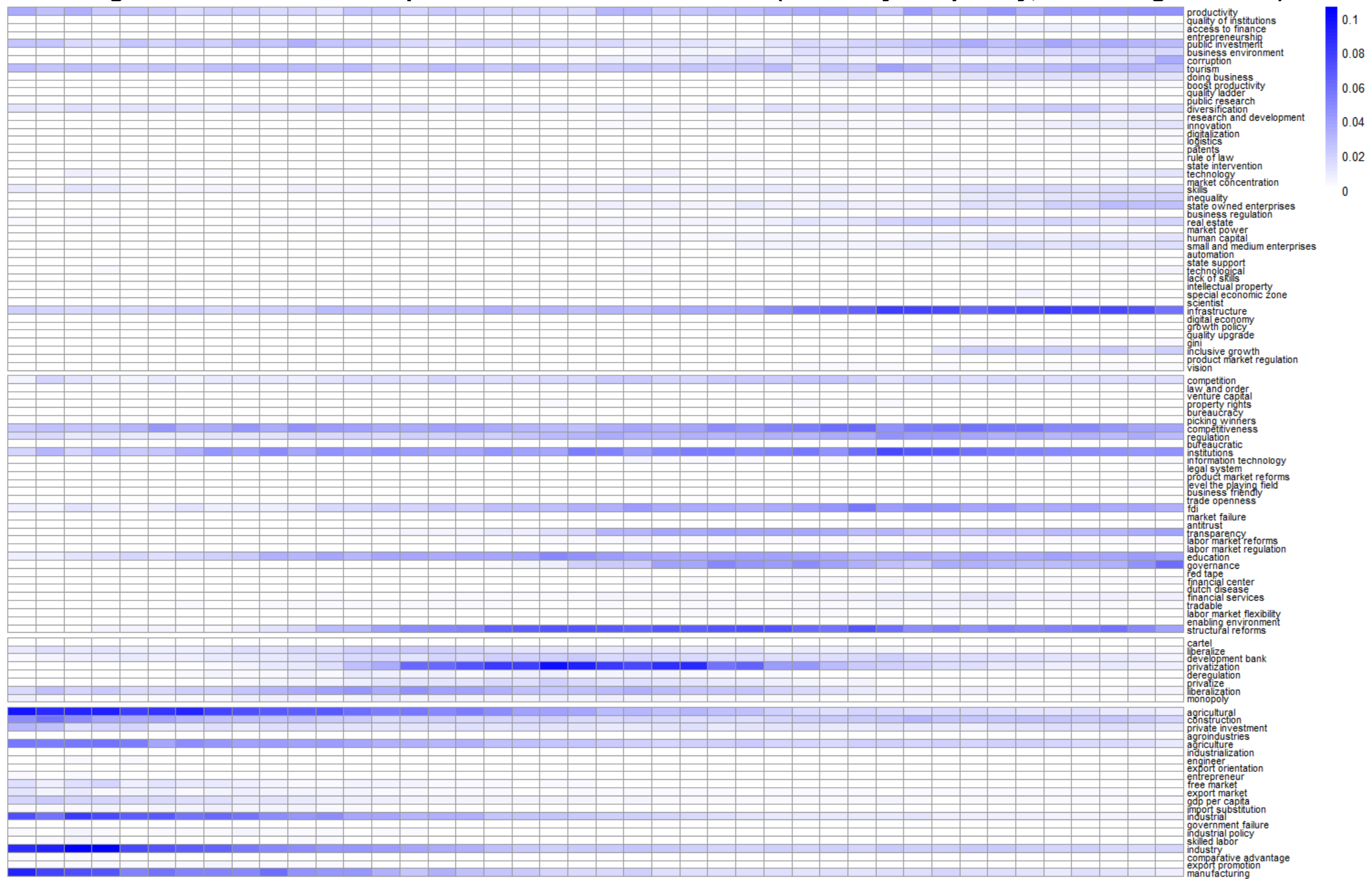

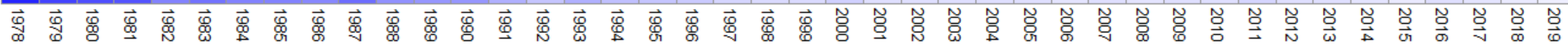




\section{Clusters as Narratives}

The identified clusters can be construed as narratives. The composition of each cluster and its dominant terms allow us to identify and name the "narrative." Similar to the interpretation of the results of the principal component analysis, this is more an art than a science.

The cluster we associate with the "Economic Structure" narrative is mostly composed of terms associated with economic sectors such as "services", "industry", "manufacturing", "agriculture" and "construction" (Figure 9). The frequencies of most of these terms have fallen consistently since the early 1980s (see also the bottom cluster of Figures 7-8). This cluster reflects a narrative in which growth is studied through the prism of the real sector, or its major industrial sectors, in other words, production or economic structure (e.g. Leontief 1966).

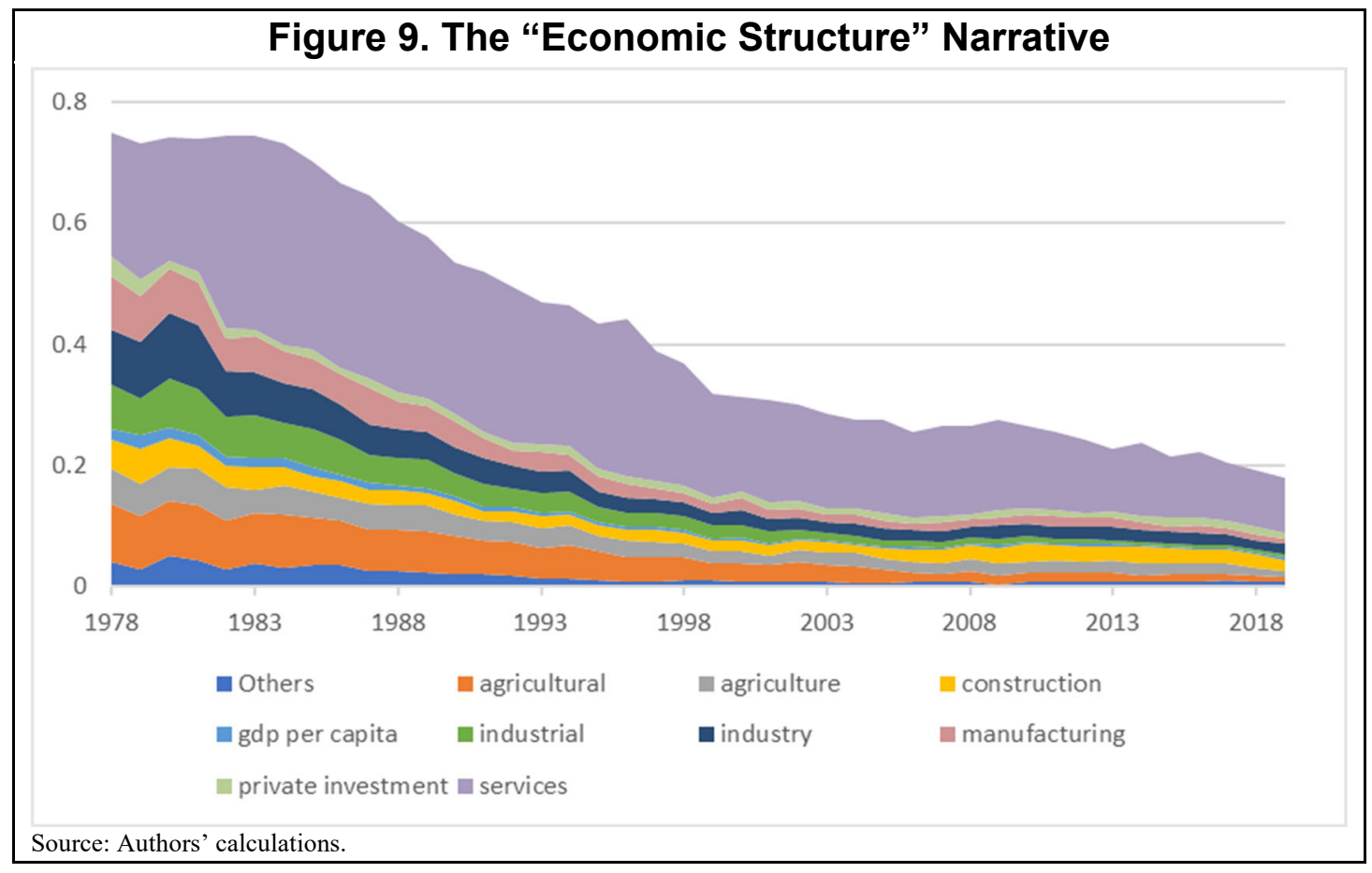

The next cluster is the most concentrated and consists mostly in terms associated with "privatization" and "liberalization" suggesting the "Washington Consensus" narrative. This is the narrative promoting the benefits of a free and unfettered market. The distribution of the cluster shows that "privatization," which dominated the cluster in terms of frequencies at its peak over the 1990s, was practically inexistent as a term until mid-1980s (Figure 10). 


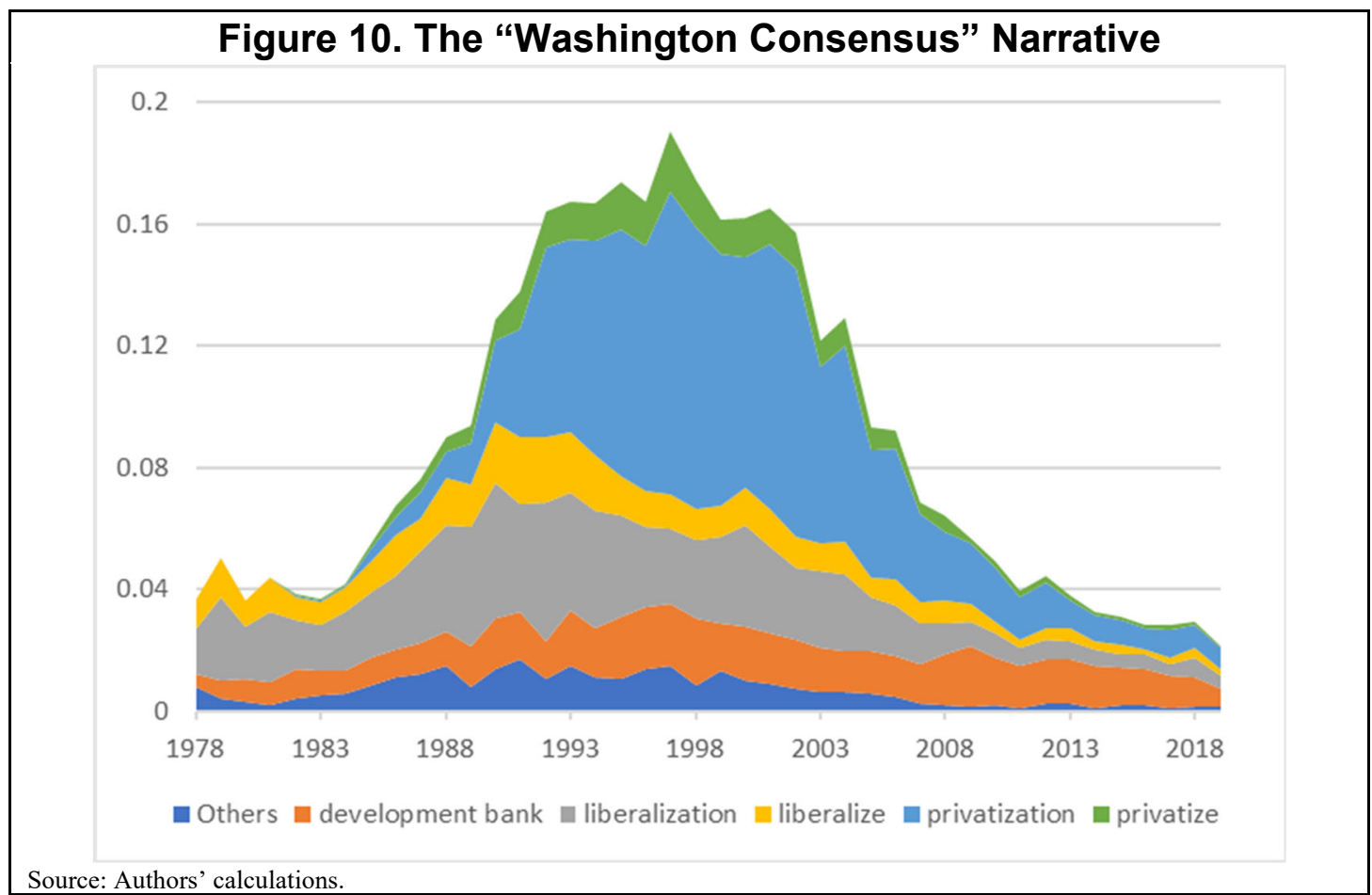

In the early 1980s, the cluster consisting mostly in terms generally associated with the "Structural Reforms" started picking up. These terms have been basic instruments in the toolbox of most professional economists to think about growth policy for the last few decades (Figure 11). This narrative reflects the importance of institutions in growth policy and outcomes, including such terms as "institutions", "governance", "regulation", and "transparency" (see Acemoglu and Robinson 2012). It also reflects the importance of "education" that emphasizes human capital as a key determinant of growth (see Lucas 1988 and Barro and Lee 2013). The cluster also includes "structural reforms", "competition", "competitiveness" and "FDI" that are considered, according to a broad consensus of economists, as key determinants of growth (see Christiansen, Schindler and Tressel 2013).

The last cluster has grown to become the largest cluster by total frequency over the last years of the sample. Its rise in the 2000s is related to the appearance of a set of terms, which were not used before (Figure 12). These include "inequality," "access to finance," "corruption," "doing business," and "business environment." Other terms such as "infrastructure" and "public investment" were used but started rising in the 2000s. We describe the narrative associated with this cluster as the "Washington Constellation." The idea that a set of seemingly unrelated concepts can be associated and made into a single narrative is not new (see Shiller 2019). As observed by Shiller, the celestial constellations we see have no objective reason to be clustered together, but they form patterns and provide a meaning for the beholder. The "Washington Constellation" could reflect this type of narrative that has come to existence since the 2000s. According to this narrative, growth can be affected by many factors while the mechanism seems relatively obscure compared to other growth narratives. In other words, the associated growth policy may suggest checking off a wide array of boxes simultaneously such as achieving a good business environment, investing in infrastructure, promoting tourism, ensuring the rule of law and access to finance, and tackling inequality. 

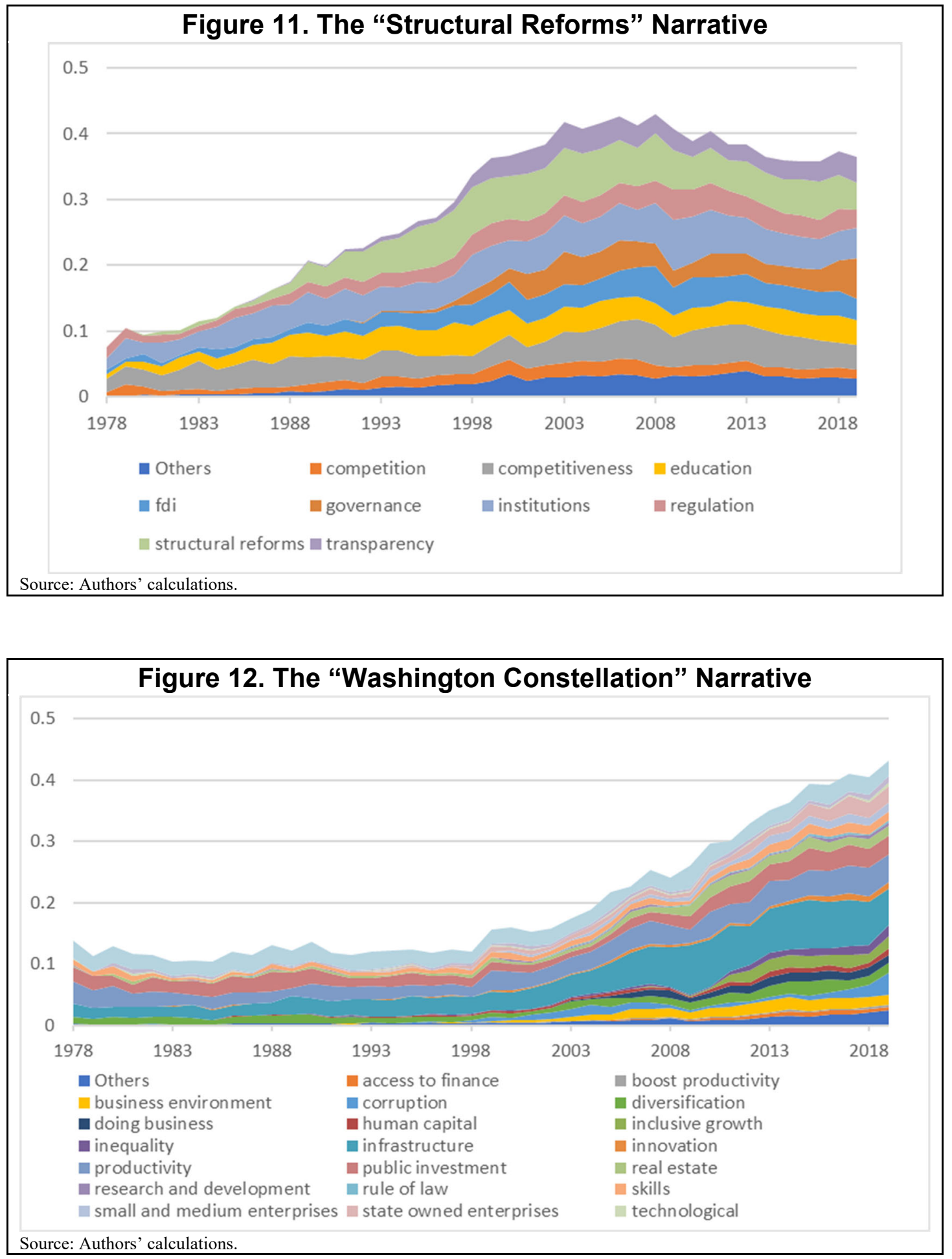

\section{E. The Rise and Fall of Growth Narratives}

There has been a stark tectonic shift in growth narratives since 1978. We track the changes in the total frequency of the four key clusters or narratives based on all the country reports available over 1978-2019. The total of relative frequencies of the four clusters is always 100 
percent, and what we unveil is the change in the emphasis or relative influence of each narrative over time (Figure 13).

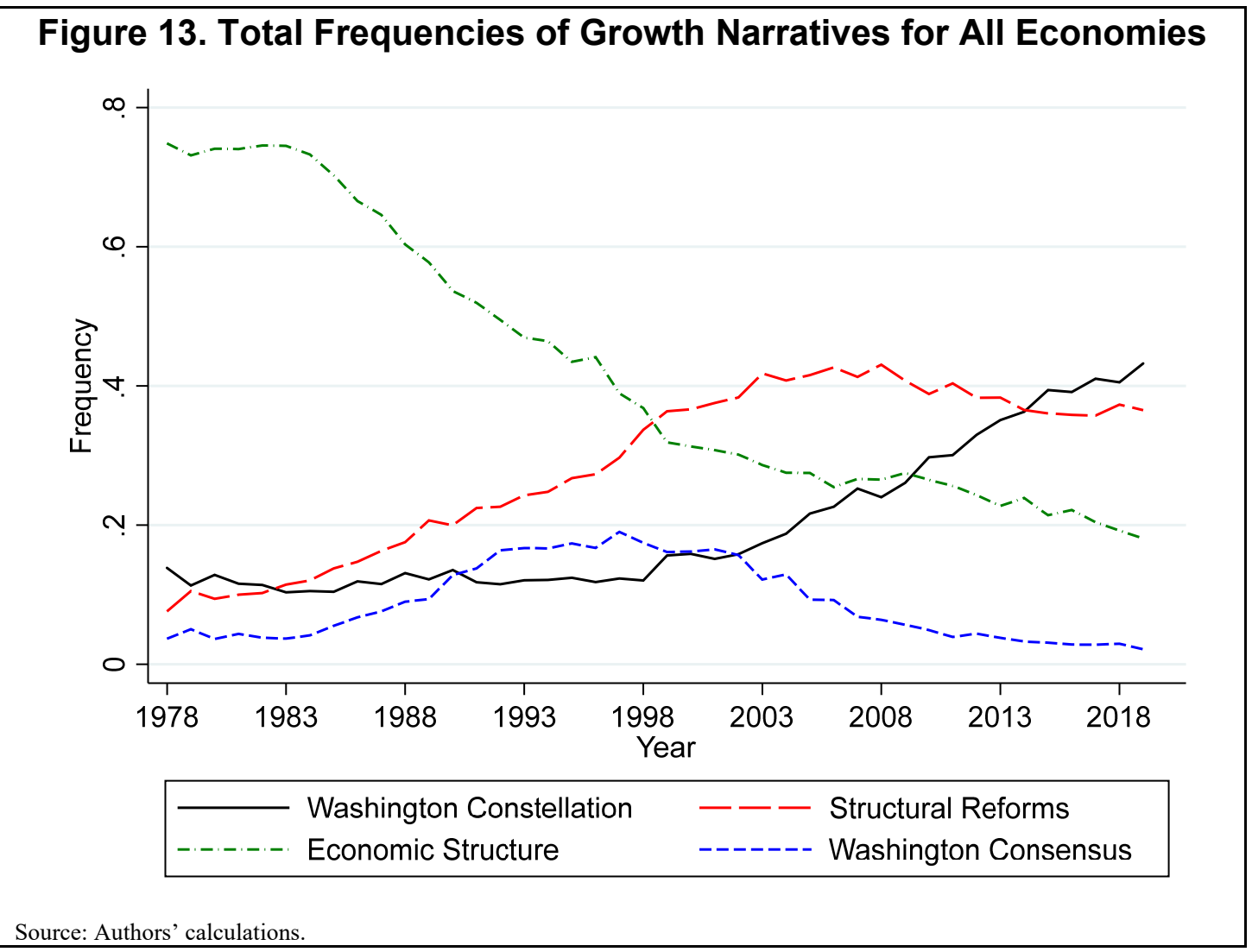

The emphasis on the production structure - that is, the discussion about the real sectors of the economy - has been on the decline since the mid-1980s. The cluster entitled "Economic Structure" was the dominant one among the four clusters representing close to 80 percent of the total in the late 1970 s to early 1980 s. Around the mid-1980s, the total frequency of this cluster started falling reaching less than 20 percent in 2019, far below other narratives.

The narrative associated with the "Washington Consensus" used to be negligible until the mid-1980s, rose to a sizable share throughout 1990s peaking around the Asian crisis of 1997 1998, and then fell out of fashion. The cluster entitled "Washington Consensus" represented a small share of the total, on average 4 percent, until around the mid-1980s. Around mid-1980s, it started rising rapidly, peaking in 1997 at 19 percent, which covers the period when many countries made their transition to market economies, especially in the Eastern Europe and the former Soviet Union. It then fell as rapidly, reaching about 2 percent by 2019 .

The "Structural Reforms" growth narrative went from a minor narrative in the mid-1980s to a dominant one in the mid-2000s. It started at around 7 percent, increased steadily over 19782003, reaching about 40 percent in the mid-2000s, and then started declining albeit at a small rate. It includes such terms as "FDI", "education", "institutions", "competitiveness", "transparency" and "governance." Interestingly, "transparency" and "governance" only started appearing in the early 1990s. This narrative was the dominant one throughout the 2000s. 
Interestingly, the 1990s and 2000s was also a period marked by a thriving literature linking institutions to growth (see Acemoglu, Johnson, and Robinson 2005 for an overview).

The narrative entitled the "Washington Constellation" emerged in parallel to the collapse of the "Washington Consensus" narrative around the Asian crisis. The "Washington Constellation" cluster is also more markedly dispersed than the others. In 2019, 23 terms represented about 90 percent of the total frequency of the cluster, while 10 terms represented the same proportion for the "Structural Reforms" and "Economic Structure" and 6 for the "Washington Consensus." A myriad of disparate terms such as "productivity", "infrastructure", "tourism," "inequality, "skills, "inclusive growth", "R\&D", "access to finance", "state owned enterprises" and "business environment" were never or barely used until they emerged after 1998. This "Washington Constellation" became the dominant narrative by 2019 , representing 40 percent of the total.

The "Structural Reforms" narrative, and to less extent the "Washington Constellation," seem to have risen at the expense of the "Economic Structure" narrative. The coefficients of correlation between the total frequencies of the associated clusters are close to -1 and -0.8 , respectively (Table 1). In other words, these two narratives are "anti-narratives" of the old "Economic Structure" narrative.

\begin{tabular}{|ccccc|}
\hline \multicolumn{5}{|c|}{ Table 1: Correlation Matrix of Clusters } \\
(coefficients of correlation)
\end{tabular}

We also detect major common turning points in the four narratives with the first turning point occurring in the mid-1980s. Using the procedure of Bai and Perron (2003) to detect endogenous structural breaks in the trends, we confirm the timing of turning points in the narratives discussed above. ${ }^{12}$ According to this procedure, the period around the mid-1980s represents a stark structural break in the both trends of "Economic Structure" and "Washington Consensus" narratives (Figures 14-15). The mid-1980s was already recognized by many observers as a period when the policy narrative shifted toward what became to be known as the Washington Consensus emphasizing low regulations, liberalization and privatization, and free markets.

${ }^{12}$ The procedure detects multiple unknown structural breaks. 
Figure 14. Endogenous Structural Breaks in the Trends: "Economic Structure"

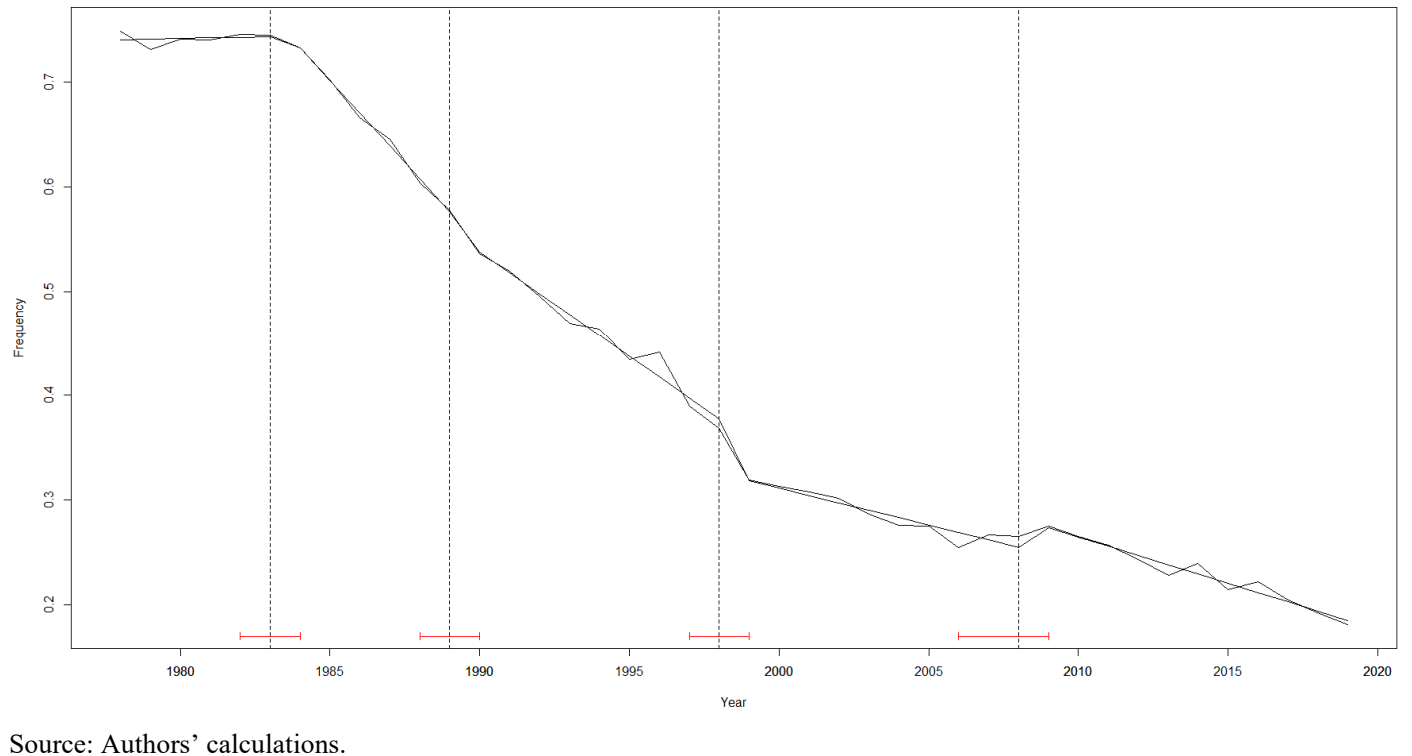

Figure 15. Endogenous Structural Breaks in the Trends: "Washington Consensus"

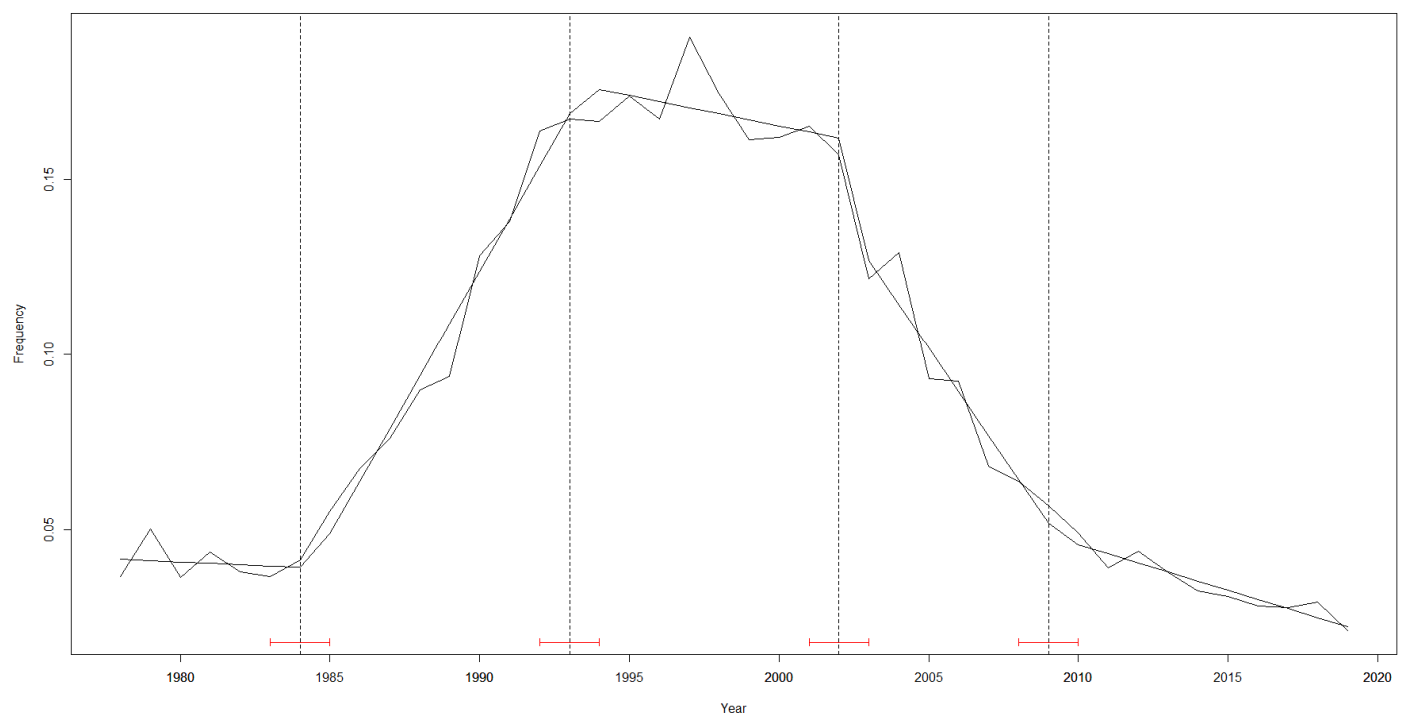

Source: Authors' calculations. 
The spread and dynamics of narratives could be affected by past theories and new evidence but also could be driven by social and political changes as observed in the 1980s. For instance, "privatization" has started rising rapidly since 1984 peaking in 1997 while worldwide privatization revenues were relatively stable in the mid-80s to early 90 s. Revenues started picking up after the mid-90s until 2000 (Estrin and Pelletier 2018). After the decline in the early 2000s, revenues started climbing again in the mid-2000s, eventually resulting in larger revenues in the 2000s and the 2010s than the 1990s. In contrast, the privatization frequency has been on a steady decline since 1997 and dropped precipitously since the early 2000s. This pattern could suggest that the concept of privatization may have become embedded in other growth concepts such as "structural reforms."

The major crises years in the 1990s and 2000s seem to be important marks in the narrative cycles. The years 1997-98, corresponding to the Asian crisis, represent another major turning point detected by the Bai-Perron procedure for the "Washington Constellation" narrative (Figure 16). These are also the years the "Washington Consensus" peaked before it started falling slowly until around 2001, when it started falling rapidly. The global financial crisis, 2008-09, or the boom years at the onset of the crisis, 2005-06, are also detected as structural breaks in multiple narratives. Yet they correspond mostly to inflection points rather than turning points except in the "Structural Reforms" narrative that starts losing its importance at the onset of the financial crisis (Figure 17).

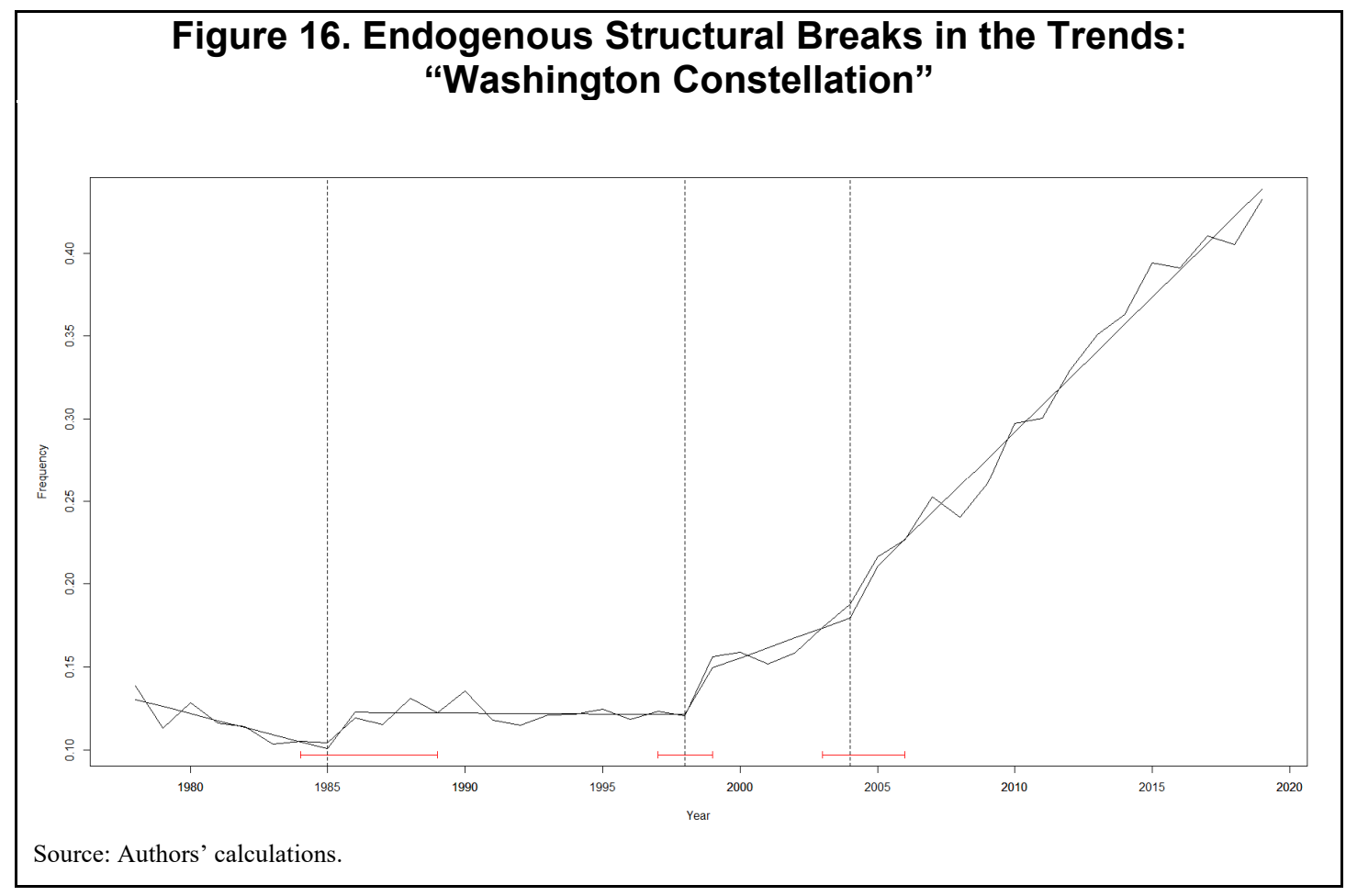




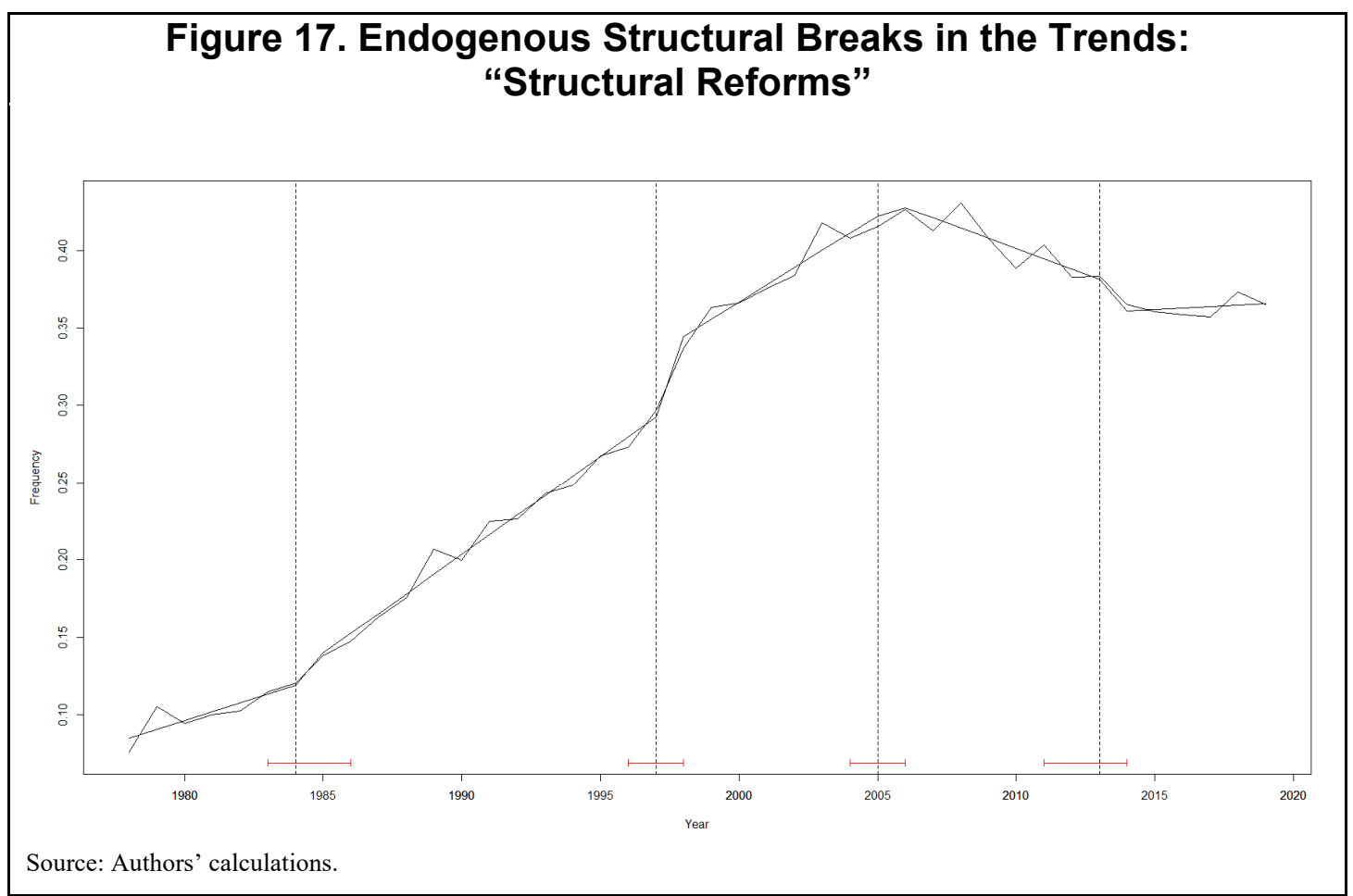

F. Industrial Policy: The Forgotten Narrative

The extent to which the state should intervene in the conduct of growth policy represents a major source of controversy among economists. The accepted wisdom is that an interventionist approach, or "industrial policy," would be misguided or too risky. The common wisdom agreed upon by professional economists is that a good growth policy consists in tackling mostly "government failures" and only a few "market failures." In other words, the state should limit its intervention to ensuring macroeconomic stability, investing in infrastructure and education, and providing a business environment that is conducive to private enterprise. In contrast, industrial policy would attempt to tackle many market failures using a broad range of instruments. These market failures could stem from externalities such as learning-by-doing, coordination failures, and information asymmetries that result in suboptimal outcomes and missing markets. The debate around industrial policy seems to have made a comeback (see Cherif and Hasanov 2019), and it is worth exploring the evolution of this narrative.

As many economic narratives spring up and fade away, so does the narrative of industrial policy. The term occurs 405 times across all income groups over 1978-2019-112 times in AMs, 172 times in EMs, and 121 times in LICs. Considering that our data span more than 4,500 reports, this is a small number of occurrences, explaining why it did not appear among the major terms in our clusters. Moreover, it is not evenly distributed, as about half of the observations across all income groups occurred before 1989. The frequency of industrial policy reached its peak in the early to mid-1980s, reaching a one percent frequency rate in AMs and EMs and about one-half of a percent overall (Figure 18). In the early 1990s, the narrative has fallen into oblivion - with the frequency falling close to zero throughout the 2000s - although the term has appeared a few times every year until 2010. Since 2012, the frequency has started picking up although it is still well below 0.2 percent. 


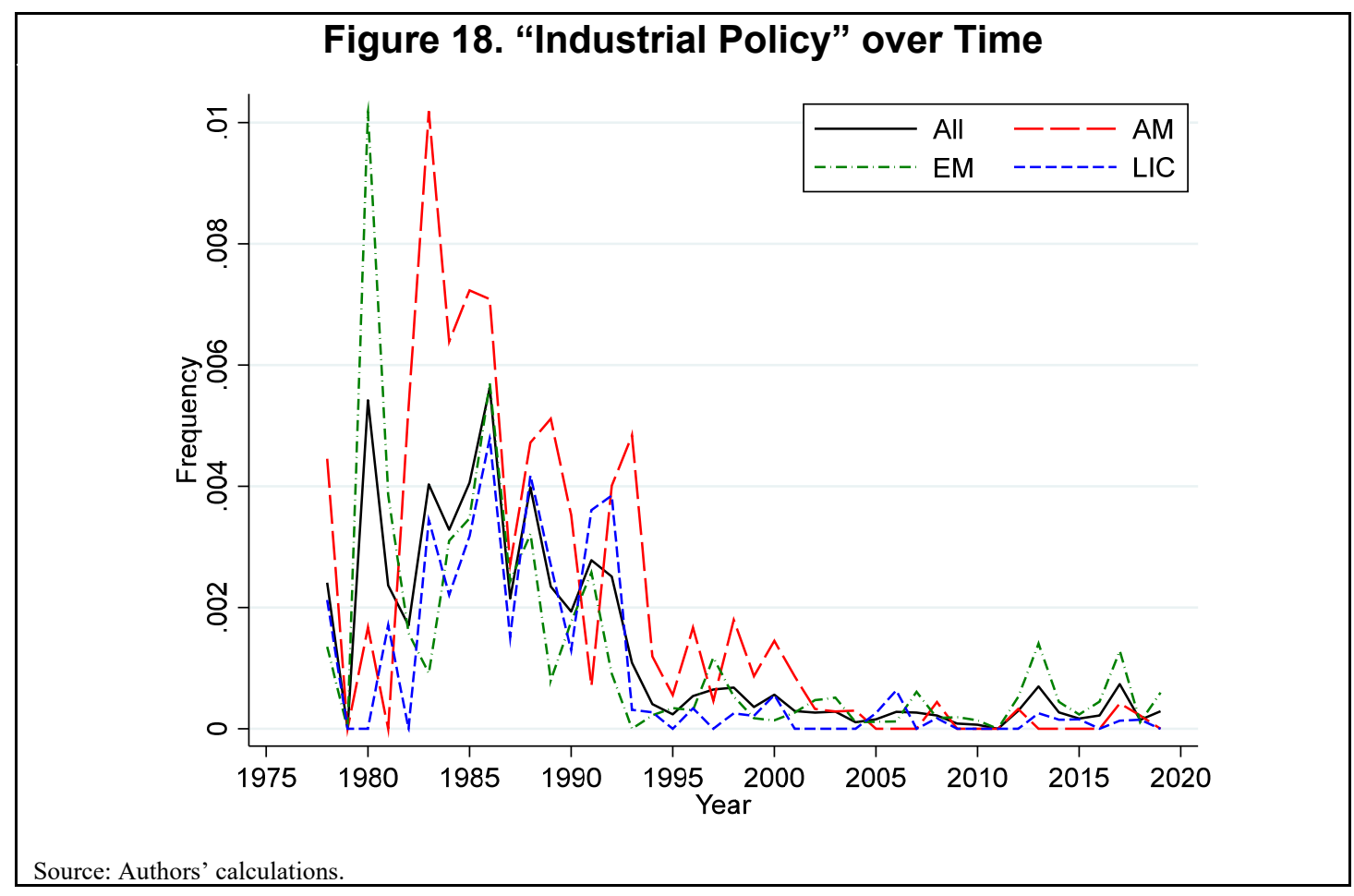

We study qualitatively the context in which industrial policy occurred in our data. The 1980s witnessed more occurrences and more neutral or positive perception of industrial policy across all income groups than during the following decades. Industrial policy was then mentioned in a context in which policymakers in EMs and LICs attempted to gear industrial policy toward supporting export industries while reducing trade protection although import substitution policies were still being pursued. The support of manufacturing and agricultural sectors was deemed important. In AMs, in addition to encouraging export orientation, especially for small and medium enterprises, policymakers discussed supporting research and innovation, new industries, and energy saving technologies, and transitioning from ailing industries or helping depressed regions. This is reminiscent of the discussion in policymaking and economic circles in AMs today, more than thirty years later. The discussion in AMs also revolved around supporting homegrown domestic firms for supplying foreign-owned export industries with inputs or services. Policy tools used included export and investment incentives, preferential credit to firms, tax deductions, sharing of technical information, and export marketing support. In EMs and LICs, international financial institutions (IFIs) provided financial support to help improve trade regulations and promote export-oriented industries.

The decline observed in the 1990s was not only in the frequency of the term but also in the application and perception of industrial policy. Since the decline of the occurrence of industrial policy in the early 1990s, the concept of industrial policy had become more attuned with a structural reform approach that started gaining ground around the same time. The application of industrial policies focused on trade and regulatory liberalization, privatization of state-owned enterprises, and horizontal policies such as improving business environment and education rather than vertical or targeted approach. The perception of industrial policy became mixed in the 1990s and had largely turned negative since the early 2000s with the comeback of a more neutral stance since 2010. 


\section{CONCLUSION}

We explore the competing narratives used by professional economists and policymakers to understand economic growth. We identify four main narratives and show that their relative influence has changed dramatically exhibiting different trends and cycles over time. We also find the patterns are similar across country groups. Since the beginning of our sample in the late 1970s and until the late 1990s, the discourse around growth was largely dominated by a narrative related to the study of economic sectors, in the spirit of Leontief (1966). Meanwhile, the "Washington Consensus" narrative, which promotes privatization and an unfettered market, used to be inexistent until the mid-1980 and then gained a sizable influence in the 1990 s, vanishing again in the 2000s. The 2000s was dominated by the "Structural Reforms" narrative, in which the quality of institutions was the key determinant of growth. This narrative was surpassed by the "Washington Constellation" narrative in the second half of the 2010s. This narrative is a constellation of various unrelated concepts such as inequality, access to finance, tourism, and doing business.

We also find that technology, innovation, and industrial policy have featured much less than institutions, governance, and structural reforms. Industrial policy has been occurring more frequently in the 1980s, reaching about one percent frequency in AMs and EMs, and has been relatively positively perceived, but has since fallen out of fashion with a potential mild comeback today. In addition, such terms as governance and transparency have not even existed in the lexicon until the 1990s and mid-1980s, respectively, and has since gained a large share of the growth discussion, reaching about 4-6 percent frequency in 2019. Lastly, key terms from growth theory such as technology and innovation and development theory such as industrialization and export-orientation have been ignored to a large extent.

The changes in narratives we observed among professional economists may be driven by a combination of factors. It could reflect learning from past experiences. For example, the crises of the 1970s and the 1980s may have accelerated the policy discussion toward more private sector participation and less state intervention. It could reflect the rise to prominence of past or new theories, potentially informed by a different interpretation of empirical evidence or new data (The Economist 2020). It could also result from the spread of a popular narrative espoused by politicians, prominent economists, or social movements. The recent neuroscience evidence shows that listening to stories and narratives synchronizes listener's brain waves with that of the storyteller and lights up many different parts of the brain. These stories could be passed onto others affecting attitudes and beliefs, changing views, and creating narratives (Renken 2020).

Shiller (2019) argues that economists should pay more attention to the effect of popular stories or narratives and how they are formed to make sense of economic phenomena. In the same vein, we suggest that economists and the public at large pay a greater attention to the formation and propagation, or contagion, of narratives among economists themselves, for they have powerful effects on societies. As Keynes in the preface to The General Theory of Employment, Interest, and Money wrote: "The difficulty lies, not in the new ideas, but in escaping from the old ones, which ramify, for those brought up as most of us have been, into every corner of our minds." 


\section{REFERENCES}

Acemoglu, Daron, Simon Johnson, and James Robinson. 2005. "Institutions as a Fundamental Cause of Long-Run Growth," in Philippe Aghion and Steven Durlauf (eds.), Handbook of Economic Growth, edition 1, volume 1, chapter 6. Elsevier: 385-472.

Acemoglu, Daron and James, Robinson. 2012. Why Nations Fail: The Origins of Power, Prosperity, and Poverty. New York: Crown.

Aghion, Philippe and Peter Howitt. 1992. "A Model of Growth Through Creative Destruction." Econometrica 60, 323-51.

Barro, Robert J. and Jong Wha Lee. 2013. "A New Data Set of Educational Attainment in the World, 1950-2010,” Journal of Development Economics 104(C), 184-198.

Cherif, Reda and Fuad Hasanov. 2019. "The Return of the Policy That Shall Not Be Named: Principles of Industrial Policy," IMF Working Papers 19/74, International Monetary Fund.

Christiansen, Lone, Martin Schindler, and Thierry Tressel. 2013. "Growth and Structural Reforms: A New Assessment,” Journal of International Economics 89(2), 347-356.

Estrin, Saul, and Adeline Pelletier. 2018. "Privatization in Developing Countries: What Are the Lessons of Recent Experience?" The World Bank Research Observer 33(1), February, 65102.

Galbraith, John K. 1967. The New Industrial State. Boston, MA: Houghton Mifflin.

Greenwood, Jeremy and Boyan Jovanovic. 1990. "Financial Development, Growth, and the Distribution of Income.” Journal of Political Economy 98(5), October, 1076-1107.

Hausmann, Ricardo, Jason Hwang, and Dani Rodrik, 2007. "What You Export Matters," Journal of Economic Growth 12(1), March, 1-25.

Kay, John. 2012. "Fetish for Making Things Ignores Real Work." Financial Times, November 13.

Leontief, Wassily. 1966. Input-Output Economics, Oxford University Press.

Lucas, Robert Jr., 1988. "On the Mechanics of Economic Development," Journal of Monetary Economics 22(1), July, 3-42.

Mamaysky, Harry. 2020. "Financial Markets and News about Coronavirus." VoxEU, CEPR's Policy Portal. August 8. Available: https://voxeu.org/article/financial-markets-and-newsabout-coronavirus.

Renken, Elena. 2020. "How Stories Connect and Persuade Us: Unleashing the Brain Power of Narrative.” NPR. April 11. Available: https://www.npr.org/sections/health- 
shots/2020/04/11/815573198/how-stories-connect-and-persuade-us-unleashing-the-brainpower-of-narrative.

Romer, Paul M. 1990. "Endogenous Technological Change," Journal of Political Economy 98(5), October, 71-102.

Rodrik, Dani. 2013. “Unconditional Convergence in Manufacturing," The Quarterly Journal of Economics 128(1), February, 165-204.

Shiller, Robert J. 2017. "Narrative Economics," American Economic Review 107(4), April, 967-1004.

Shiller, Robert J. 2019. Narrative Economics: How Stories Go Viral and Drive Major Economic Events. Princeton, NJ: Princeton University Press.

Solow, Robert M. 1957. "Technical Change and the Aggregate Production Function," The Review of Economics and Statistics 39(3), 312-320.

The Economist. 2020. "Economics Sometimes Changes Its Mind." August 6. Available: https://www.economist.com/leaders/2020/08/06/economics-sometimes-changes-its-mind.

Ward, J. H. 1963. "Hierarchical Grouping to Optimize an Objective Function." Journal of the American Statistical Association 58, 236-244.

Williamson, John. 1990. "What Washington Means by Policy Reform" in Latin American Adjustment: How Much Has Happened. John Williamson (ed.). Washington: Institute for International Economics. 
Appendix Table 1. Input Vocabulary and Average Frequency (1978-2019)

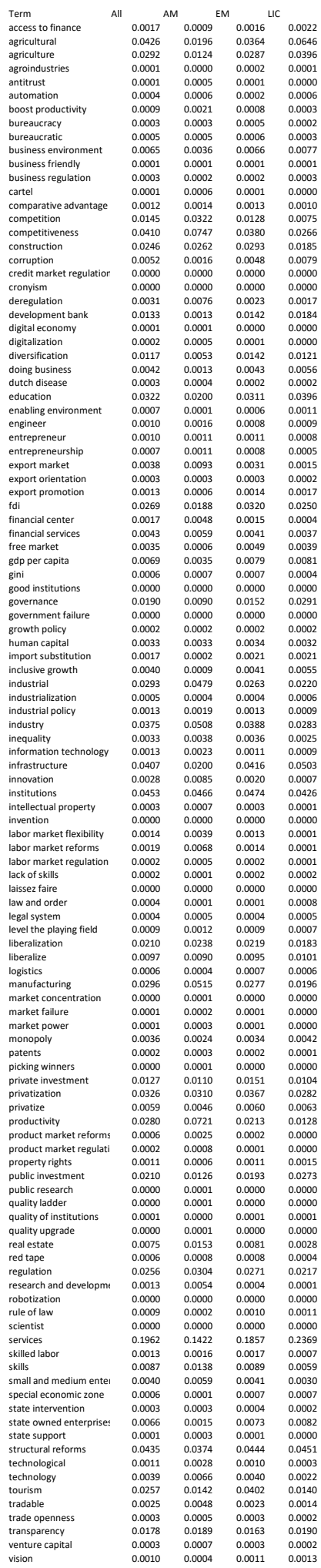

CInternational Monetary Fund. Not for Redistribution 